\title{
Diversidade de fungos zoospóricos da Reserva Biológica de Mogi Guaçu, estado de São Paulo, Brasil ${ }^{1}$
}

\author{
Diversity of zoosporic fungi at the "Reserva Biológica de Mogi Guaçu", São Paulo, Brazil
}

\author{
Cristiane de Almeida Nascimento ${ }^{2,3}$ \& Carmen Lidia Amorim Pires-Zottarelli ${ }^{2}$
}

\begin{abstract}
Resumo
Realizou-se o levantamento da diversidade de fungos zoospóricos em duas áreas de Cerrado, com estados de preservação distintos, na Reserva Biológica de Mogi Guaçu, estado de São Paulo. Quatro coletas trimestrais de água e solo foram realizadas em seis pontos por área, durante as estações chuvosa (janeiro e outubro de 2008) e seca (abril e julho de 2008). Utilizando a técnica de iscagem múltipla com substratos celulósicos, quitinosos e queratinosos, específica para o isolamento de fungos aeróbicos sapróbios e parasitas, foram obtidos 434 espécimes representados por 38 espécies dos filos Blastocladiomycota, Chytridiomycota e Oomycota, dentre as quais, 31 são primeiras citações para a Reserva. Os resultados encontrados ampliam o conhecimento da ocorrência destes organismos em áreas de Cerrado no estado de São Paulo e no Brasil, complementando estudos realizados anteriormente na Reserva.
\end{abstract}

Palavras-chave: Cerrado, Chromista, Chytridiomycota, Fungi, Oomycota.

\begin{abstract}
Two areas of Cerrado ("A" and "B") at different preservation stages were selected at the "Reserva Biológica de Mogi Guaçu”, São Paulo state, to survey zoosporic fungi diversity. Water and soil samples were collected during the rainy (January and October 2008) and dry seasons (April and July 2008), every three months, at six sampling sites in areas " $A$ " and "B". 434 specimens were obtained using the multiple baiting technique with cellulosic, chitinous and keratinous substrates, which are specific for the isolation of aerobic, parasitic or saprobial fungi. 38 species were identified, belonging to Blastocladiomycota, Chytridiomycota and Oomycota. Of these, 31 species are cited for the reserve for the first time. The results increased our knowledge of the occurrence of the organisms from Cerrado in São Paulo state and Brazil, complementing previous studies in the Reserve.
\end{abstract}

Key words: Cerrado, Chromista, Chytridiomycota, Fungi, Oomycota.

\section{Introdução}

O termo fungos zoospóricos não é considerado categoria taxonômica ou linhagem evolutiva e vem sendo utilizado de forma didática para se referir aos organismos heterotróficos flagelados, cuja diversidade está estimada em aproximadamente 1.988 espécies, amplamente distribuídas nos mais diversos ecossistemas aquáticos e terrestres, onde ocorrem como sapróbias, parasitas ou mutualistas. Estão distribuídos em três Reinos, baseados em estudos morfológicos e moleculares: Reino Fungi, com os filos Chytridiomycota e Blastocladiomycota, os quais possuem esporos com um flagelo simples e posterior, e Neocallimastigomycota, que apresenta esporos poliflagelados; Reino Chromista (Straminipila pro parte), com os filos Labyrinthulomycota (Labyrinthista) e Oomycota, com esporos biflagelados, um simples e o outro franjado, inseridos lateral ou apicalmente, e Hyphochytriomycota, com esporos com um flagelo

\footnotetext{
${ }^{1}$ Parte da tese de Doutorado da primeira autora, Programa de Pós-graduação em Biodiversidade Vegetal e Meio Ambiente do Instituto de Botânica, São Paulo, SP, Brasil.

${ }^{2}$ Núcleo de Pesquisa em Micologia, Instituto de Botânica, C.P. 68041, 04045-972, São Paulo, SP, Brasil.

${ }^{3}$ Autor para correspondência: crisbotanic@yahoo.com.br
} 
franjado, anteriormente inserido; e por fim Reino Protozoa, com o filo Plasmodiophoromycota, apresentando esporos biflagelados, simples e apicalmente inseridos (Kirk et al. 2008).

Embora vários estudos de diversidade destes organismos tenham sido realizados no Brasil, o conhecimento do grupo no país ainda é pequeno, especialmente se considerarmos os diferentes biomas. Até o momento, 348 táxons foram relatados, sendo 120 pertencentes a Chytridiomycota, 197 a Oomycota, 18 a Blastocladiomycota, cinco a Hyphochytriomycota, quatro a Labyrinthulomycota e quatro a Plasmodiophoromycota (Milanez et al. 2007; Nascimento et al. 2011 a,b). A Mata Atlântica foi o bioma mais investigado nos estudos taxonômicos, revelando a expressiva diversidade dos fungos zoospóricos (Milanez et al. 2007; Nascimento \& Pires-Zottarelli 2009). Apesar dos poucos estudos realizados no Cerrado, a diversidade destes organismos neste bioma também se mostrou relevante (Milanez 1968; Milanez et al. 1997).

Visando a conservação de sua flora e fauna, em 7 de janeiro de 1942, pelo Decreto Estadual $n^{\circ}$ 12.500, as antigas fazendas Campininha e Capitinga, situadas em Mogi Guaçu, foram desapropriadas para constituir uma Reserva do Estado de São Paulo. Em agosto de 1970, outro decreto governamental transferiu 470,4 hectares dessas terras ao Instituto de Botânica, formando a atual Reserva Biológica de Mogi Guaçu, constituída por duas áreas designadas de "A" e "B" (Secretaria do Meio Ambiente 2000). Gomes et al. (2003) e Baptista et al. (2004) identificaram, respectivamente, 20 espécies da família Saprolegniaceae e nove espécies do gênero Pythium isoladas de amostras de água e solo, coletadas apenas na área "A" da Reserva.

Nos últimos anos, o Cerrado, considerado o segundo maior bioma do Brasil, sofreu intenso desmatamento com o avanço do processo de urbanização e de atividades agropecuárias. Especialmente no Estado de São Paulo, esta devastação foi bastante significativa. Áreas que no início do século ocupavam $14 \%$ do território paulista, atualmente cobrem menos de $1 \%$ e somente $0,2 \%$ estão protegidos em 32 unidades de conservação estaduais (Ratter et al. 1997; Durigan et al. 2004; Mendonça 2004).

O presente estudo foi realizado com o objetivo de inventariar os táxons de fungos zoospóricos das áreas "A" e "B" da Reserva Biológica de Mogi Guaçu, nas estações chuvosa e seca.

\section{Material e Métodos}

Caracterização da área de estudo

A Reserva Biológica de Mogi Guaçu possui duas áreas (denominadas "A" e "B", sensu Secretaria do Meio Ambiente (2000)) e está localizada no município de Mogi Guaçu (22 $18^{\circ} \mathrm{S}$ e $\left.47^{\circ} 11^{\prime} \mathrm{W}\right)$, estado de São Paulo, sendo caracterizada por inverno seco e verão chuvoso. Separadas por uma distância de aproximadamente $3 \mathrm{~km}$, as duas áreas da Reserva são cobertas por vegetação de Cerrado, apresentando o Córrego do Cortado na área " $\mathrm{A}$ " e o Córrego Capitinguinha na área "B". Enquanto diversos estudos de biodiversidade foram desenvolvidos na área "A", a área "B" foi considerada como setor "intocável" até recentemente, sendo mais preservada que a área anterior (De Vuono et al. 1982). Mais detalhes da descrição das áreas de estudo, incluindo mapas geográficos, temperatura do ar e condições de precipitação, podem ser consultados em Nascimento et al. (2011a).

Amostragem, isolamento, identificação morfológica e preservação dos fungos zoospóricos

Foram realizadas quatro coletas de água e de solo, trimestralmente, na estação chuvosa (janeiro e outubro de 2008) e na estação seca (abril e julho de 2008), em seis pontos pré-demarcados na área " $A$ " $e$ seis na área "B". Com auxílio de frascos de Wheaton $(100 \mathrm{~mL})$, amostras de água dos córregos $(\mathrm{n}=48)$ foram coletadas a uma profundidade de até $10 \mathrm{~cm}$, juntamente com detritos vegetais e animais. Também foram coletadas amostras de aproximadamente $300 \mathrm{~g}$ de solo $(n=48)$, após remoção da serapilheira, com o auxílio de pá de jardinagem, a uma profundidade de até $15 \mathrm{~cm}$, e acondicionadas em sacos plásticos. Imediatamente após as coletas, essas amostras foram processadas no laboratório, utilizando a técnica de iscagem múltipla, específica para o isolamento de fungos aeróbicos sapróbios e parasitas (Sparrow Jr. 1960, Milanez 1989). Alíquotas de $30 \mathrm{~mL}$ de cada amostra de água foram transferidas para placas de Petri, juntamente com materiais orgânicos vegetais (folhas, pequenos galhos, frutos) e animais (insetos) presentes nas amostras. De cada amostra de solo, $30 \mathrm{~g}$ foram dissolvidos em cerca de $40 \mathrm{~mL}$ de água destilada e esterilizada, em placas de Petri com diâmetro de $9 \mathrm{~cm}$. Em seguida, em cada placa contendo as amostras, foram adicionados dois fragmentos $\left(1 \mathrm{~cm}^{2}\right)$ de epiderme de cebola, palha de milho, celofane, exoesqueleto de camarão, ecdise de cobra, além de uma semente partida ao meio de 
Sorghum sp., alguns fios de cabelo e uma pequena porção de grãos de pólen. As amostras foram incubadas a temperatura de $20-22^{\circ} \mathrm{C}$, controlada por ar condicionado. Cada isca foi colocada sobre lâmina, com uma gota de água destilada e esterilizada, e coberta com lamínula para ser examinada ao microscópio, a partir do quinto dia de incubação até a identificação dos espécimes. Para cada mês de coleta, 24 placas de Petri (12 de cada área), com oito tipos de iscas listadas acima, foram analisadas.

Os espécimes de fungos zoospóricos foram purificados em meios de cultura previamente autoclavados: $\mathrm{MP}_{5}$ ( $4 \mathrm{~g}$ de maltose, $1 \mathrm{~g}$ de peptona, $15 \mathrm{~g}$ de ágar e $1.000 \mathrm{~mL}$ de água destilada) e CMA (17 g de ágar fubá ou "corn meal agar" da Oxoid e $1.000 \mathrm{~mL}$ de água destilada com adição de $0,2 \mathrm{~g}$ de penicilina $\mathrm{G}$ (benzilpenicilina)), $0,1 \mathrm{~g}$ de sulfato de estreptomicina puro e $0,02 \mathrm{~g}$ de cloridrato de vancomicina, depois da autoclavagem). Devido à dificuldade de crescimento em meio de cultura, alguns táxons foram purificados pela transferência múltipla para novos substratos. Espécimes que cresceram em meio de cultura foram preservados em frascos Wheaton com água destilada esterilizada (Milanez 1989), pelo método de Castellani (Figueiredo \& Pimentel 1975) e em tubos inclinados com meios de cultura semelhantes aos utilizados no isolamento. Estes espécimes foram incorporados à Coleção de Culturas de Algas, Fungos e Cianobactérias do Instituto de Botânica de São Paulo (CCIBt). Lâminas semipermanentes dos espécimes que não cresceram em meio de cultura foram montadas com lactofenol e azul de algodão, e incorporadas ao Herbário do Instituto de Botânica (SP).

Os táxons foram identificados de acordo com Sparrow Jr. (1960), Karling (1977), van der Plaats-Niterink (1981) e Johnson Jr. et al. (2002), e descrições originais das espécies. Após identificação, os táxons foram documentados por meio de captura de imagem Leica Qwin V3 acoplado

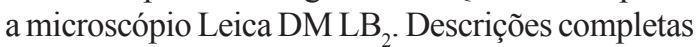
foram feitas apenas para espécies não descritas na literatura. Para as outras, foram incluídas referências que apresentam descrição completa da espécie, selecionadas dentre as mais recentes. Os dados de distribuição geográfica apresentados para cada espécie foram baseados em Forzza et al. (2010).

\section{Resultados e Discussão}

Trinta e oito espécies de fungos zoospóricos foram identificadas, a partir da observação de
434 iscas colonizadas. Destas, 16 espécies são pertencentes ao Reino Chromista, Filo Oomycota, e 22 espécies ao Reino Fungi, Filos Blastocladiomycota e Chytridiomycota (Tab. 1).

\section{CHROMISTA (STRAMINIPILA pro parte) OOMYCOTA LEPTOMITALES LEPTOLEGNIELLACEAE}

Leptolegniella keratinophila Huneycutt, J. Elisha Mitchell Sci. Soc. 68: 110. $1952 . \quad$ Fig. 1a

Descrição: Gomes \& Pires-Zottarelli (2008). Material examinado: Reserva Biológica de Mogi Guaçu, amostras de solo da área "B", 28.I.2008, 28.VII.2008, em ecdise de cobra, C.A. Nascimento (SP 393743).

Ocorre no Amazonas, Piauí, Pernambuco, São Paulo.

A característica principal da espécie é a formação dos esporos de resistência dentro de hifas irregulares, que formam um micélio extensivo e ramificado, em substrato queratinoso, sem delimitação de zoosporângios, o que foi observado nos espécimes isolados, concordando com a descrição original de Huneycutt (1952). No Brasil, a espécie foi reportada pela primeira vez por Milanez (1970), a partir de amostras de solo dos municípios de Cândido Mota, Cruzália Paulista e Pedrinhas (SP).

\section{OLPIDIOPSIDALES OLPDIOPSIDACEAE}

Olpidiopsis achlyae McLarty, Bull. Torrey Bot. Club 68: 62. 1941. Fig. $1 \mathrm{~b}$

Talo holocárpico, monocêntrico, endobiótico, causando hipertrofia das células do hospedeiro. Zoosporângios lisos, ovóides, 22,5-5,0 × 17,5-27,5 $\mu \mathrm{m} ; 1-2$ tubos de descarga. Esporos de resistência ornamentados, esféricos, castanhos, 27,5-30,0 $\mu \mathrm{m}$ diâmetro; ornamentações franjadas ou fibrilares; células companheiras ausentes.

Material examinado: Reserva Biológica de Mogi Guaçu, amostra de água da área "A", parasitando Achlya proliferoides Coker, 28.I.2008, C.A. Nascimento.

Ocorre no Piauí, Minas Gerais, São Paulo.

As principais características da espécie são a presença de zoosporângios lisos, ovóides, e esporos de resistência com ornamentações franjadas ou fibrilares, concordando com Sparrow Jr. (1960). Foi encontrada pela primeira vez no Brasil, parasitando Achlya flagellata Coker, em amostras de água coletadas por Rogers et al. (1970) em São Paulo (SP).

A preservação do espécime não foi possível por problemas de contaminação. 
के

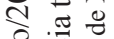

可

을 흔

(ब)

可不

的路

के

\&

ते

을 11

馬

更

就

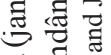

诺

全

0 过定

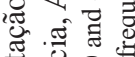

के

要

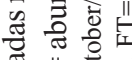

要

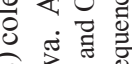

文矛恶

$\|$ 幽 政

ङ

品䨌

o

品 क人

II

$\Xi$ है $\Xi$

苛吕言

웅

䒕 需

के

है थ

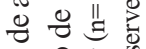

की \&

要

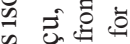

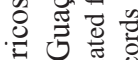

항.

定帘

果 *

हี

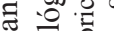

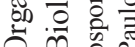

120

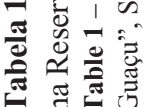

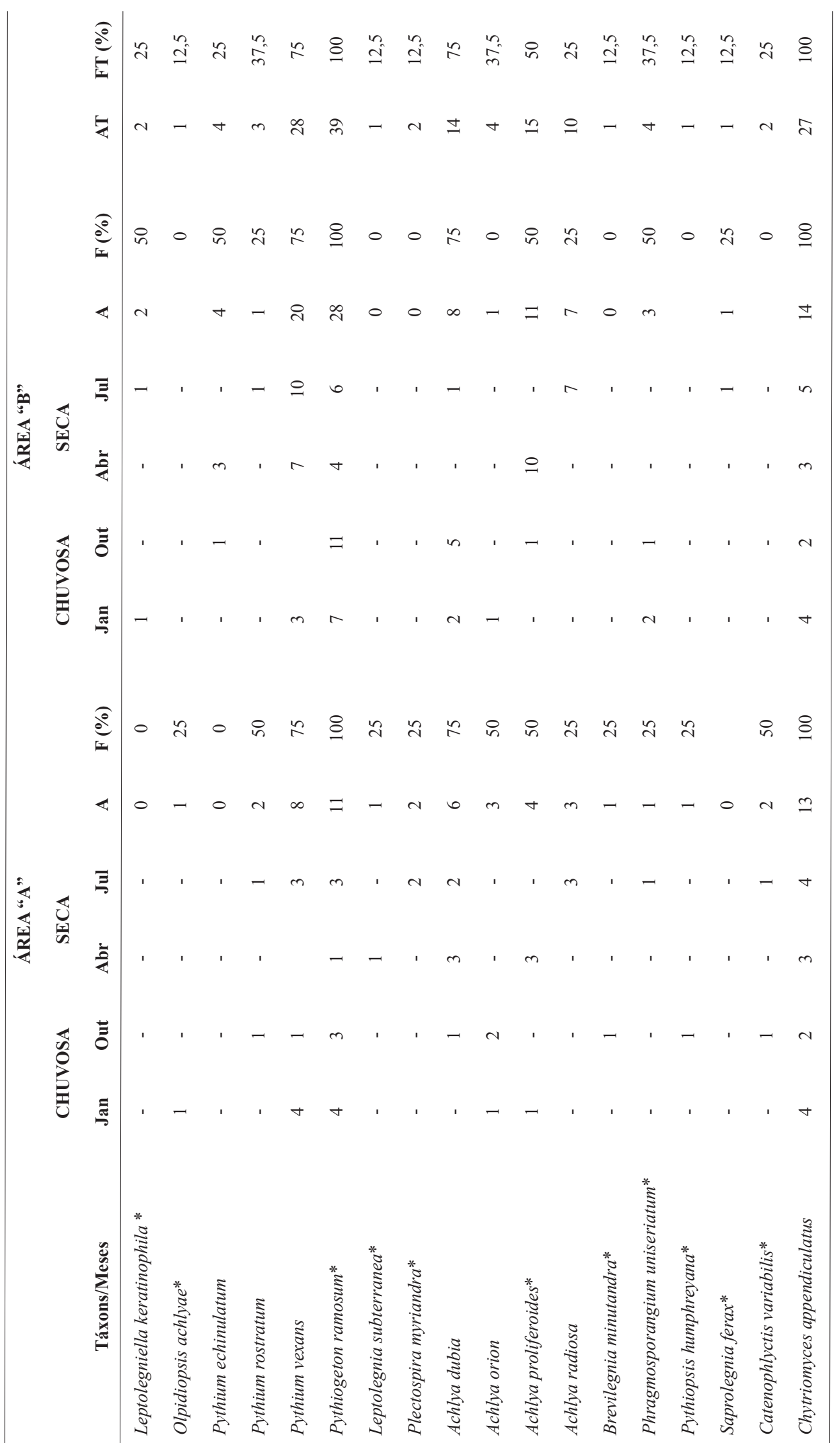

Rodriguésia 63(3): 587-611.2012 


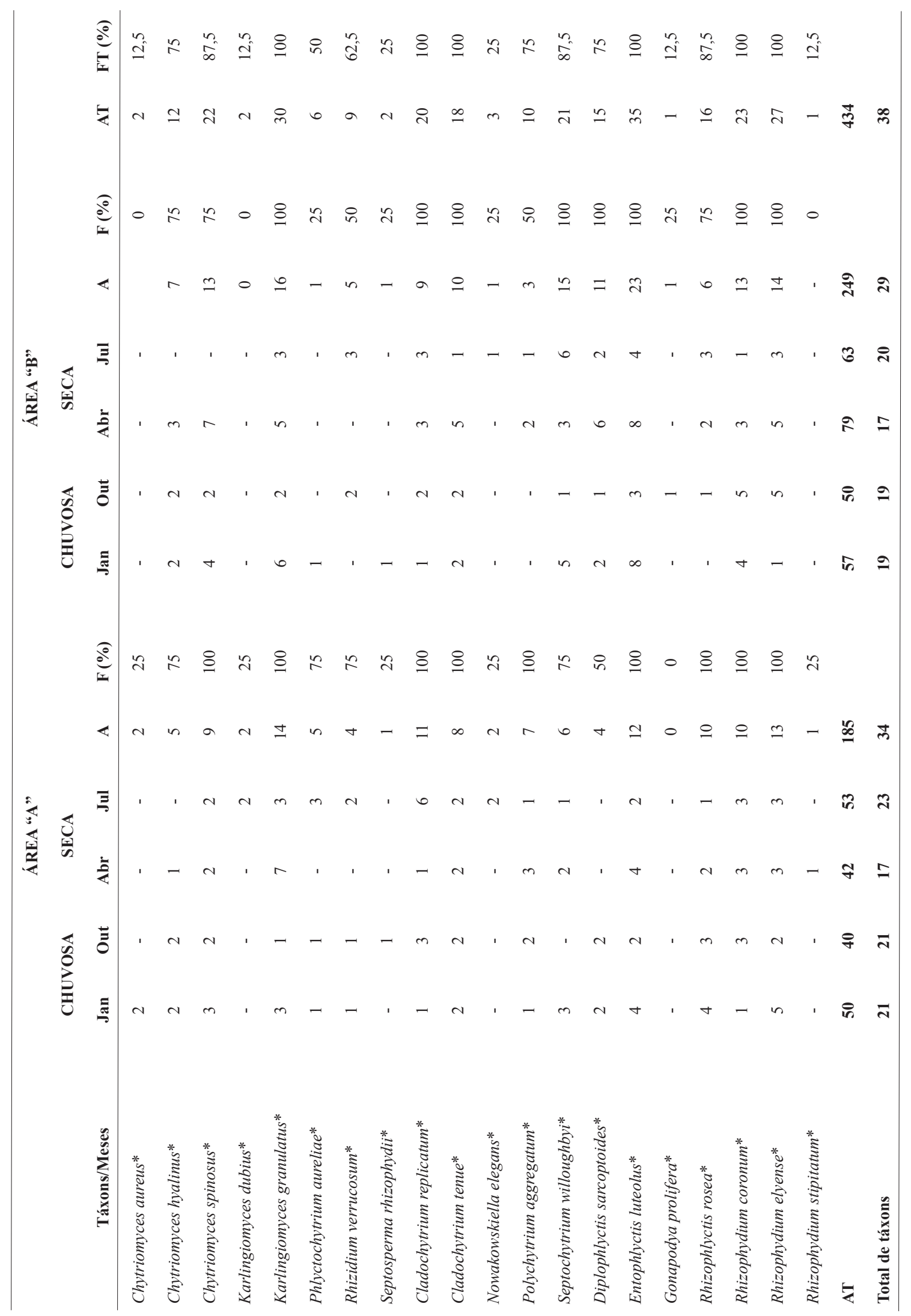



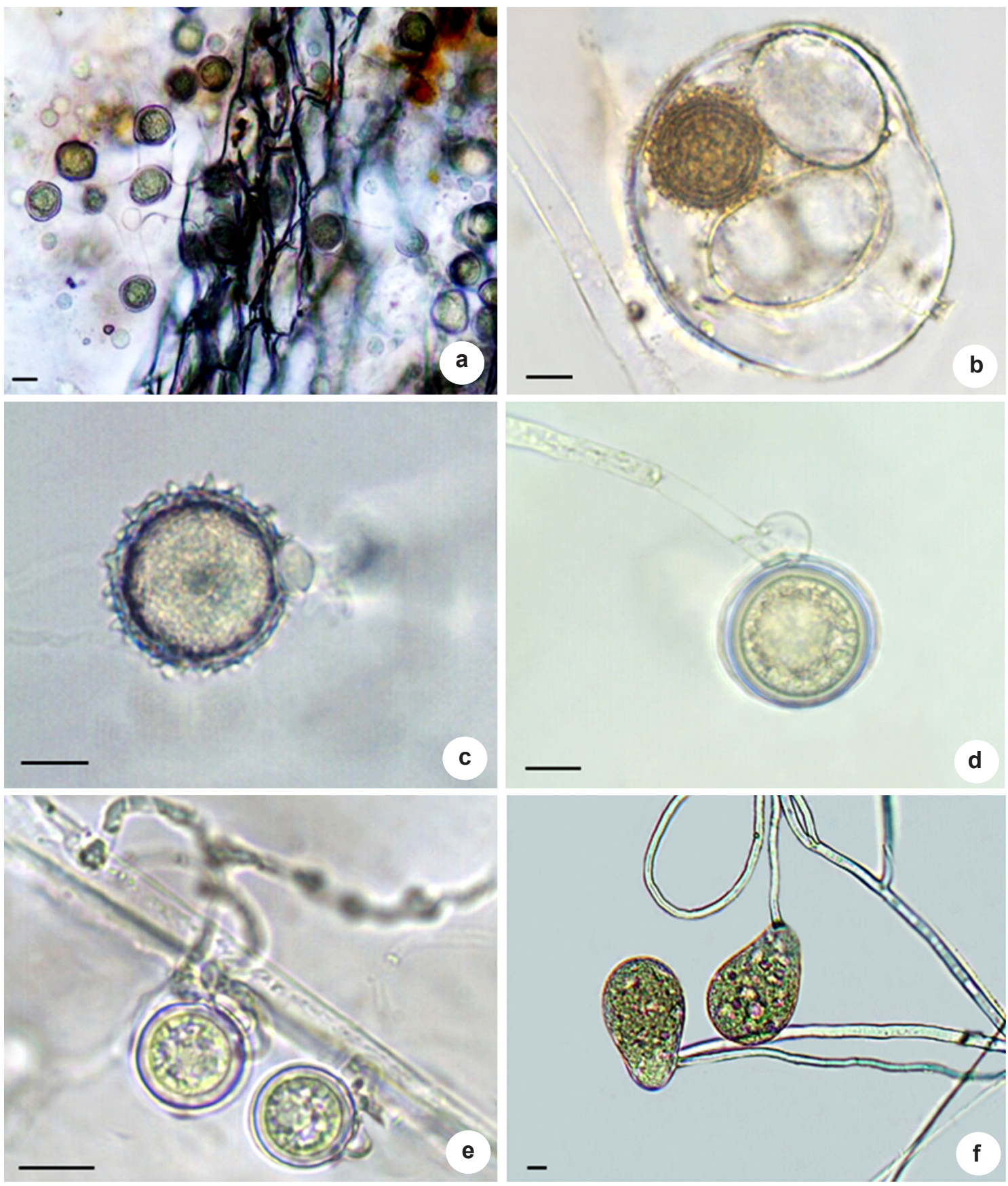

Figura 1 - Fungos zoospóricos da Reserva Biológica de Mogi Guaçu, São Paulo, Brasil. a. Leptolegniella keratinophila Huneycutt - Esporos de resistência em ecdise de cobra; b. Olpidiopsis achlyae McLarty - Zoosporângios vazios e esporo de resistência em oogônio de Achlya proliferoides. c. Pythium echinulatum V.D. Matthews - Oogônio ornamentado com anterídio hipógino. d. P. rostratum E.J. Butler - Oogônio com anterídio monóclino séssil. e. P. vexans de Bary - Oogônios com célula anteridial irregular e em forma de sino. f. Pythiogeton ramosum Minden - Zoosporângios. Barras: $10 \mu \mathrm{m}$.

Figure 1 - Zoosporic fungi of the "Reserva Biológica de Mogi Guaçu", São Paulo State, Brazil. a. Leptolegniella keratinophila Huneycutt - Resting spores in snake skin. b. Olpidiopsis achlyae McLarty - Empty zoosporangia and resting spore in oogonium of Achlya proliferoides. c. Pythium echinulatum V.D. Matthews - Ornamented oogonium with hypogynous antheridium. d. P. rostratum E.J. Butler - Oogonium with sessile monoclinous antheridium. e. P. vexans de Bary - Oogonia with bell-shaped antheridial cell. f. Pythiogeton ramosum Minden - Zoosporangia. Bars: $10 \mu \mathrm{m}$. 


\section{PYTHIALES}

\section{PYTHIACEAE}

Pythium echinulatum V.D. Matthews, Studies on the Genus Pythium, p. 101. $1931 . \quad$ Fig. 1c

Descrição: Miranda \& Pires-Zottarelli (2008). Material examinado: Reserva Biológica de Mogi Guaçu, amostras de solo da área "B", 28.IV.2008 e 20.X.2008, em semente de Sorghum sp., epiderme de cebola e palha de milho, C.A. Nascimento (CCIBt 2313).

Ocorre no Piaú, Pernambuco, São Paulo.

A espécie se caracteriza, principalmente, pela presença de oogônios com ornamentações espinhosas e anterídios monóclinos e hipóginos, os quais foram encontrados nos espécimes examinados, concordando com van der Plaats-Niterink (1981). No entanto, a ausência de ornamentações nos oogônios foi mencionada por Baptista et al. (2004). Foi descrita pela primeira vez para o Brasil por M.S. Cavalcanti, isolada de amostras de água e solo, coletadas em Recife (PE) (Milanez et al. 2007).

Pythium rostratum E.J. Butler, Memoirs of the Dept. Agr. India, Bot. s. 1: 84. $1907 . \quad$ Fig. 1d

Descrição: Miranda \& Pires-Zottarelli (2008). Material examinado: Reserva Biológica de Mogi Guaçu, amostras de solo das áreas "A" e "B", 28.VII.2008 e 20.X.2008, em semente de Sorghum sp., C.A. Nascimento (CCIBt 2317).

Ocorre no Piauí, Pernambuco, Minas Gerais, Rio de Janeiro, São Paulo.

As principais características da espécie são a presença de zoosporângios sem proliferação interna, oogônios intercalares, frequentemente catenulados e com anterídios sésseis, o que foi observado nos espécimes isolados, concordando com van der Plaats-Niterink (1981). Foi reportada pela primeira vez no Brasil por Joffily (1947), a partir de amostras de solo coletadas em Campinas (SP).

Pythium vexans de Bary, J. Bot. Paris 14: 105. 1876.

Fig. 1e

Descrição: Miranda \& Pires-Zottarelli (2008). Material examinado: Reserva Biológica de Mogi Guaçu, amostras de água da área "B", 28.IV.2008 e 28.VII.2008, e de solo das áreas "A" e "B", 28.I.2008, 28.IV.2008, 28.VII.2008 e 20.X.2008, em semente de Sorghum sp., epiderme de cebola, palha de milho e ecdise de cobra, C.A. Nascimento (CCIBt 2289).

Ocorre no Piauí, Pernambuco, Rio de Janeiro, São Paulo.

A espécie se caracteriza pela presença de zoosporângios esféricos, sem proliferação interna e anterídios monóclinos com células anteridiais irregulares, tipicamente em forma de sino, os quais foram facilmente observados nos espécimes isolados, concordando com a descrição de van der PlaatsNiterink (1981). No Brasil, a espécie foi isolada pela primeira vez por P.C.T. Carvalho, em 1965, a partir de raízes apodrecidas de Strelitzia sp. coletadas em Cotia (SP) (Milanez et al. 2007).

\section{PYTHIOGETONACEAE}

Pythiogeton ramosum Minden, Falck, Mykol. Unters. Berichte 1: 243. 1916.

Fig. 1f

Descrição: Gomes \& Pires-Zottarelli (2008). Material examinado: Reserva Biológica de Mogi Guaçu, amostras de água das áreas "A" e "B", 28.I.2008, 28.IV.2008, 28.VII.2008, 20.X.2008, e de solo da área "B", 28.I.2008, 20.X.2008, em semente de Sorghum sp., epiderme de cebola, palha de milho, celofane, ecdise de cobra e exoesqueleto de camarão, C.A. Nascimento (SP 416573).

Ocorre no Amazonas, Piauí, Pernambuco, Rio de Janeiro, São Paulo.

A presença de zoosporângios terminais, frequentemente irregulares, ou raramente ovais, formando ângulo reto com a hifa de inserção e a ausência de reprodução sexuada são as principais características da espécie, corroborando o descrito por Sparrow Jr. (1960). Foi isolada pela primeira vez no Brasil por Beneke \& Rogers (1970), a partir de detritos vegetais do Parque Nacional de Itatiaia, Rio Janeiro (RJ).

\section{SAPROLEGNIALES \\ LEPTOLEGNIACEAE}

Leptolegnia subterranea Coker \& J.V. Harvey, in Harvey, J. Elisha Mitchell Sci. Soc. 41: 158. 1925.

Fig. 2a

Descrição: Gomes \& Pires-Zottarelli (2006). Material examinado: Reserva Biológica de Mogi Guaçu, amostra de solo da área "A", 28.IV.2008, em epiderme de cebola, C.A. Nascimento.

Ocorre em São Paulo.

As principais características da espécie são a presença de oogônios com papilas, oósporos subexcêntricos e a ausência de anterídios, as quais foram verificadas no espécime isolado. No Brasil, foi isolada pela primeira vez por Gomes \& PiresZottarelli (2006), a partir de amostras de solo coletadas em Santo André (SP).

Devido à contaminação, o espécime não foi preservado.

Plectospira myriandra Drechsler, J. Agric. Res., Washington 34: 295. 1927.

Fig. 2 b-c

Material examinado: Reserva Biológica de Mogi Guaçu, amostra de água da área "A", 28.VII.2008, em semente de Sorghum sp. e epiderme de cebola, C.A. Nascimento. 

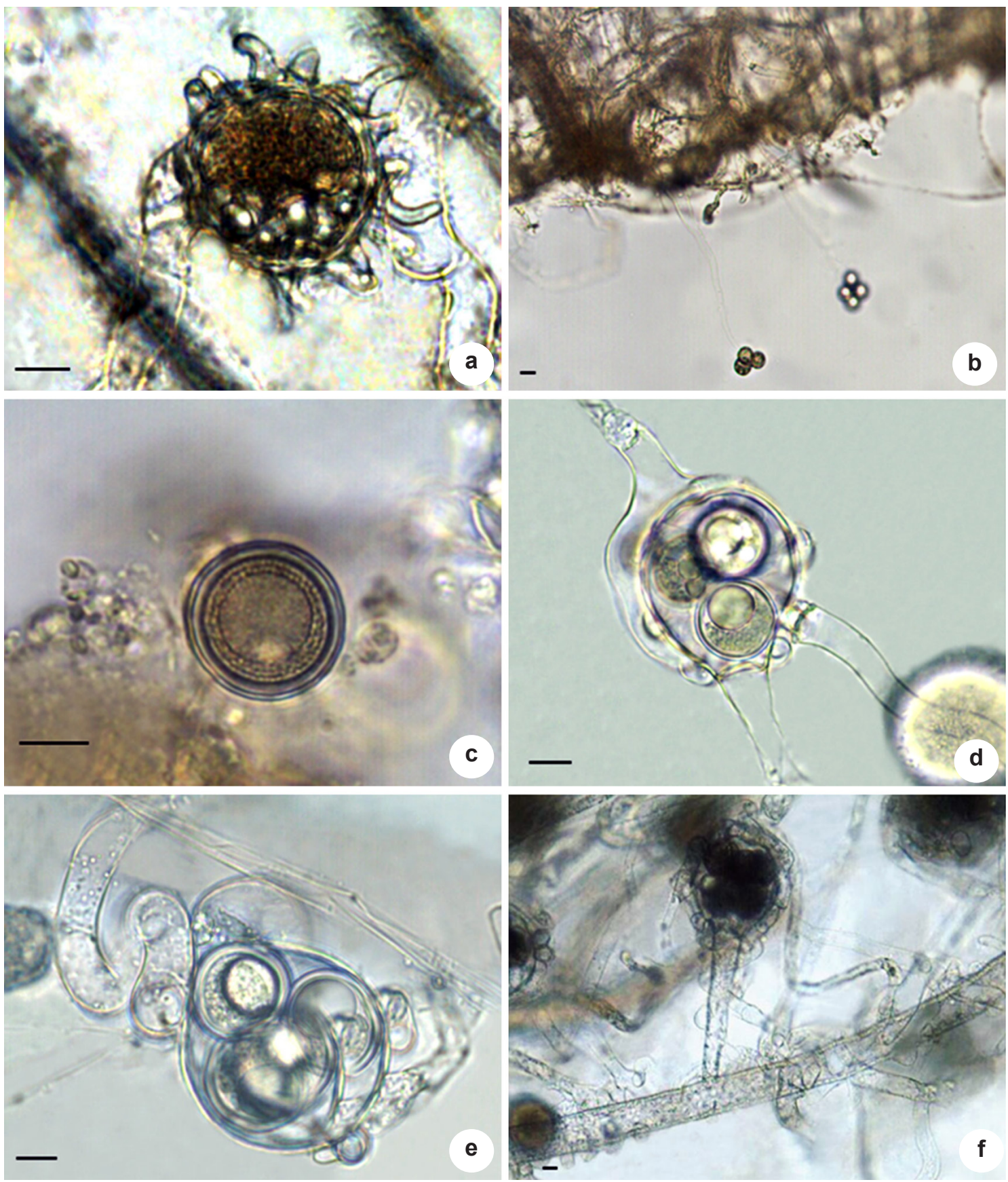

Figura 2 - Fungos zoospóricos da Reserva Biológica de Mogi Guaçu, São Paulo, Brasil. a. Leptolegnia subterranea Coker \& J.V. Harv - Oogônio com papilas e oósporo subexcêntrico. b-c. Plectospira myriandra Drechsler - b. Zoosporângios com liberação aclióide em palha de milho; c. Oogônio com oósporo subcêntrico. d. Achlya dubia Coker - Oogônio com anterídios díclinos e oósporos excêntricos. e. Achlya orion Coker \& Couch - Oogônio com oósporos excêntricos e pedúnculo retorcido. f. Achlya proliferoides Coker-Oogônio com ramos anteridiais enrrolando na hifa, pedúnculo oogonial e oogônios. Barras: $10 \mu \mathrm{m}$.

Figure 2-Zoosporic fungi of the "Reserva Biológica de Mogi Guaçu", São Paulo State, Brazil. a. Leptolegnia subterranea Coker \& J.V. Harv - Oogonia with papillate wall and subeccentric oospore. Figures b-c. Plectospira myriandra Drechsler - b. Zoosporangia with achlyoid spore release in corn leaves; c. Oogonium with subcentric oospore. d. Achlya dubia Coker - Oogonia with diclinous antheridia and eccentric oospores. e. Achlya orion Coker \& Couch - Oogonium with eccentric oospores and coiled stalk. f. Achlya proliferoides Coker-Oogonia with antheridial branches in the hypha, oogonial stalks and oogonia. Bars: $10 \mu \mathrm{m}$. 
Ocorre no Piauí, São Paulo.

A espécie caracteriza-se pela presença de zoosporângios lobulados formando complexos, zoósporos encistando no ápice do zoosporângio, oogônios amarelados com oósporos subcêntricos, com a presença ou ausência de anterídios, características observadas no espécime examinado, concordando com a monografia de Johnson Jr. et al. (2002).

Devido a problemas de contaminação, a espécie não foi preservada.

\section{SAPROLEGNIACEACE}

Achlya dubia Coker, Saprolegniaceae with notes on other water molds, p. 135. 1923.

Fig. 2d

Descrição: Gomes et al. (2003).

Material examinado: Reserva Biológica de Mogi Guaçu, amostras de água das áreas "A" e "B", 28.I.2008, 28.IV.2008, 28.II.2008 e 20.X.2008, e de solo da área "B", 20.X.2008, em semente de Sorghum sp. e epiderme de cebola, C.A. Nascimento (CCIBt 2314).

Ocorre em Minas Gerais, São Paulo.

A espécie se caracteriza pela presença de zoosporângios primários liberando de forma traustotecóide e aclióide, com alguns secundários apresentando liberação dictióide, e oósporos excêntricos, os quais foram verificados nos espécimes examinados, concordando com Johnson Jr. et al. (2002). A primeira citação da espécie para o Brasil é de Beneke \& Rogers (1962), que a isolaram de amostra de água coletada em Viçosa (MG).

Achlya orion Coker \& Couch, J. Elisha Mitchell Scient. Soc. 36: 100. 1920.

Fig. 2e

Descrição: Gomes \& Pires-Zottarelli (2008). Material examinado: BRASIL. SÃO PAULO: Mogi Guaçu, Reserva Biológica de Mogi Guaçu, amostras de água da área "A", 28.I.2008 e 20.X.2008, e de solo da área "B", 28.I.2008, em semente de Sorghum sp., C.A. Nascimento (CCIBt 2285).

Ocorre no Amazonas, Piauí, Pernambuco, Minas Gerais, São Paulo.

A presença de oósporos excêntricos com pedúnculo oogonial pendente e/ou retorcido caracteriza a espécie. As características dos isolados examinados concordam com Johnson Jr. et al. (2002). Foi isolada pela primeira vez no Brasil por Beneke \& Rogers (1962) de amostras de água do Parque Estadual das Fontes do Ipiranga, São Paulo (SP).

Achlya proliferoides Coker, Saprolegniaceae with notes on other water molds, p. 115. 1923. Fig. 2f

Descrição: Gomes et al. (2003).
Material examinado: Reserva Biológica de Mogi Guaçu, amostras de água das áreas "A" e "B", 28.I.2008, 20.IV.2008 e 20.X.2008, em semente de Sorghum sp., epiderme de cebola, palha de milho, exoesqueleto de camarão e ecdise de cobra, C.A. Nascimento (CCIBt 2290).

Ocorre no Amazonas, Piauí, Pernambuco, Minas Gerais, São Paulo, Paraná.

As principais características da espécie são: oósporos excêntricos, ramos anteridiais díclinos e monóclinos, os quais se enrolam nas hifas, pedúnculos oogoniais e oogônios, o que foi observado nos espécimes examinados, concordando com Johnson Jr. et al. (2002). Foi originalmente descrita no Brasil por Beneke \& Rogers (1962), isolada de amostras de água coletadas em Viçosa (MG).

Achlya radiosa Maurizio, Mitt. Deutsch. FischereiVereins 7: 57. 1899.

Fig. 3a

Descrição: Gomes \& Pires-Zottarelli (2008). Material examinado: Reserva Biológica de Mogi Guaçu, amostras de água das áreas "A" e "B", 28.VII.2008, em semente de Sorghum sp., epiderme de cebola, palha de milho, exoesqueleto de camarão e ecdise de cobra, C.A. Nascimento (CCIBt 2309).

Ocorre no Mato Grosso do Sul, Rio de Janeiro, São Paulo.

A espécie é facilmente reconhecida pela presença de oogônios com ornamentações mamiformes e duplo-mamiformes, oósporos subcêntricos e anterídios andróginos, os quais foram observados nos espécimes isolados, concordando com Johnson Jr. et al. (2002). Foi descrita pela primeira vez no Brasil como Achlya pseudoradiosa por Rogers \& Beneke (1962) e, devido às formas das ornamentações oogoniais, foi colocada em sinonímia com Achlya radiosa por Johnson Jr. et al. (1975).

Brevilegnia minutandra Honhk, Veröff. Ins. Meeresf., Bremerhaven 1: 127. 1952. Fig. 3b-c

Micélio difuso e pouco extensivo. Hifas delicadas e gemas ausentes. Zoosporângios abundantes, cilíndricos, fusiformes ou clavados, 42,5-200,0 × 5,0-17,5 $\mu \mathrm{m}$; renovação simpodial. Zoósporos dispostos em uma a três fileiras no zoosporângio; liberação dos zoósporos brevilegnióide, zoósporos encistados, 7,5-22,5 $\mu \mathrm{m}$ de diâmetro. Oogônios laterais ou terminais, ocasionalmente sésseis, predominantemente esféricos, (7,5) 15,0-17,5 (25,0) $\mu \mathrm{m}$ de diâmetro; parede oogonial lisa; pedúnculo simples, frequentemente curto, 2,0-7,5 $\mu \mathrm{m}$ de comprimento. Ramos anteridiais raramente produzidos; quando 


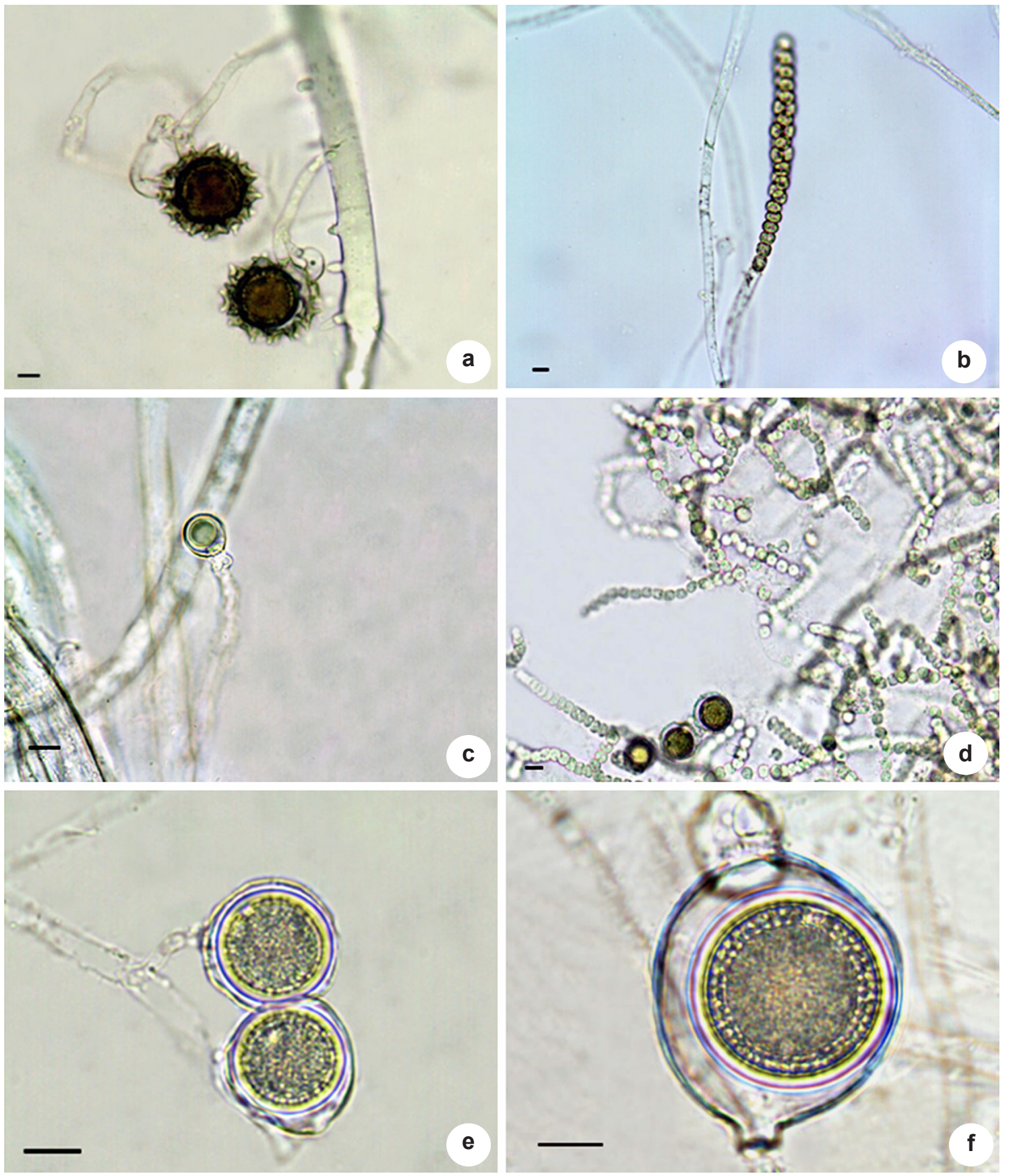

Figura 3 - Fungos zoospóricos da Reserva Biológica de Mogi Guaçu, São Paulo, Brasil. a Achlya radiosa Maurizio - Oogônios ornamentados e anterídios andróginos. b-c. Brevilegnia minutandra Höhnk - b. Zoosporângio; c. Oogônio com oósporo excêntrico. d-e. Phragmoporangium uniseriatum R.L. Seym. - d. Aspecto geral em ecdise de cobra evidenciando zoosporângios e oogônios; e. Oogônios com oósporos cêntricos. f. Pythiopsis humphreyana Coker - Oogônio com oósporo cêntrico. Barras: $10 \mu \mathrm{m}$.

Figure 3-Zoosporic fungi of the "Reserva Biológica de Mogi Guaçu", São Paulo State, Brazil. a. Achlya radiosa Maurizio - Ornamented oogonia and androgynous antheridia. b-c. Brevilegnia minutandra Höhnk - b. Zoosporagium; c. Oogonium with eccentric oospore. d-e. Phragmosporangium uniseriatum R.L. Seym. - d. Zoosporangia and oogonia in snake skin; e. Oogonia with centric oospores. f. Pythiopsis humphreyana Coker - Oogonium with centric oospore. Bars: $10 \mu \mathrm{m}$. 
presentes, andróginos e extremamente pequenos, originando-se muito próximo ao septo basal do oogônio. Células anteridiais raramente produzidas; quando presentes, 1 por oogônio, cilíndricas, curtas e muito inconspícuas; atracação lateral; tubos de fertilização não observados. Oósporos excêntricos, esféricos, (5,0) 12,5-15,0 (22,5) $\mu \mathrm{m}$ de diâmetro; 1 por oogônio.

Material examinado: Reserva Biológica de Mogi Guaçu, amostras de solo da área "A", 20.X.2008, em semente de Sorghum sp., C.A. Nascimento (CCIBt 3351).

Ocorre no Amazonas.

Anterídios raramente produzidos ou ausentes, quando presentes andróginos; abundante presença de zoosporângios fusiformes ou clavados, com 1-3 fileiras de zoósporos, e oogônios lisos são características da espécie, as quais foram verificadas no espécime isolado neste estudo, concordando com Johnson Jr. et al. (2002). Foi citada pela primeira vez no Brasil por I.L. Silva, a partir de amostras de solo coletadas em Manaus (AM) (Milanez et al. 2007).

\section{Phragmosporangium uniseriatum R.L. Seym.,} Mycotaxon 92: 8. 2005.

Fig. 3d-e

Descrição: Pires-Zottarelli et al. (2007a).

Material examinado: Reserva Biológica de Mogi Guaçu, amostras de solo das áreas "A" e "B", 28.I.2008, 28.VII.2008 e 20.X.2008, em semente de Sorghum sp. e ecdise de cobra, C.A. Nascimento (CCIBt 2291).

Ocorre em Minas Gerais, São Paulo.

A espécie se caracteriza pela presença de zoosporângios com uma e duas fileiras, originados a partir da conversão de uma hifa inteira, geralmente com liberação dictióide dos zoósporos; oogônios com parede lisa, irregular ou papilada e com oósporos cêntricos e subcêntricos. Johnson Jr. et al. (2005) observaram espécimes de Phragmosporangium unisseriatum com zoósporos dispostos em uma fileira dentro do zoosporângio, oósporos subcêntricos e oogônios irregulares. No Brasil, a espécie foi isolada pela primeira vez por Pires-Zottarelli et al. (2007a), de amostras coletadas em Cubatão e Santo André (SP) e Ingaí (MG). Neste trabalho, as autoras verificaram que, além das características mencionadas por Johnson Jr. et al. (2005), espécimes brasileiros também apresentaram, em menor proporção, zoósporos dispostos em duas fileiras dentro do zoosporângio, oósporos cêntricos, oogônios lisos a papilados e coloração amarelada dos oogônios e oósporos com bastante frequência.
Pythiopsis humphreyana Coker, Mycologia 6: 292. 1914.

Fig. $3 \mathrm{f}$

Descrição: Gomes \& Pires-Zottarelli (2008). Material examinado: Reserva Biológica de Mogi Guaçu, amostras de solo da área "B", 20.X.2008, em epiderme de cebola, C.A. Nascimento (SP 416034).

Ocorre no Amazonas, Minas Gerais, São Paulo.

Anterídios andróginos, oósporos cêntricos e subcêntricos, e oogônios lisos ou com papilas são características marcantes da espécie, as quais foram observadas no espécime isolado, estando de acordo com Johnson Jr. et al. (2005). A espécie foi isolada pela primeira vez no Brasil por J. M. Oliveira de amostras de solo coletadas em Ingaí (MG) (Milanez et al. 2007).

Saprolegnia ferax (Gruith.) Thur., Ann. Sci. Nat., Bot. 14: 214. 1850.

Fig. 4a-b

Basiônimo: Conferva ferax Gruith., Nova Acta Acad. Leop.-Carol. 10: 445. 1821.

Descrição: Gomes et al. (2003).

Material examinado: Reserva Biológica de Mogi Guaçu, amostra de água da área "B", 28.VII.2008, em semente de Sorghum sp., C.A. Nascimento s.n. 2315 (CCIBt), coleta 20.VII.2008, área "B", amostra de solo iscada com semente de Sorghum sp.

Ocorre em Pernambuco, Minas Gerais, Rio de Janeiro, São Paulo.

A espécie se caracteriza pela presença de poros na parede do oogônio, anterídios raros, quando presentes monóclinos ou andróginos, e oósporos subcêntricos e cêntricos, os quais foram verificados nos espécimes examinados, concordando com Johnson Jr. et al. (2002). Foi descrita pela primeira vez no Brasil por H.P. Upadhyay, em 1967, como Saprolegnia floccosa Maurizio, isolada de amostras de solo em Caruaru (PE), e como Saprolegnia bernadensis Harvey, isolada de amostras de solo em Ouricuri (PE) (Milanez et al. 2007).

\section{FUNGI \\ BLASTOCLADIOMYCOTA BLASTOCLADIALES CATENARIACEAE}

Catenophlyctis variabilis (Karling) Karling, Am. J. Bot. 52: 134. 1965.

Fig. $4 \mathrm{c}$

Basiônimo: Phlyctorhiza variabilis Karling, Am. J. Bot. 34: 27. 1947.

Descrição: Nascimento \& Pires-Zottarelli (2010).

Material examinado: Reserva Biológica de Mogi Guaçu, amostra de água da área "A", 28.VII.2008 e 20.X.2008, em ecdise de cobra, C.A. Nascimento (SP 393734). 

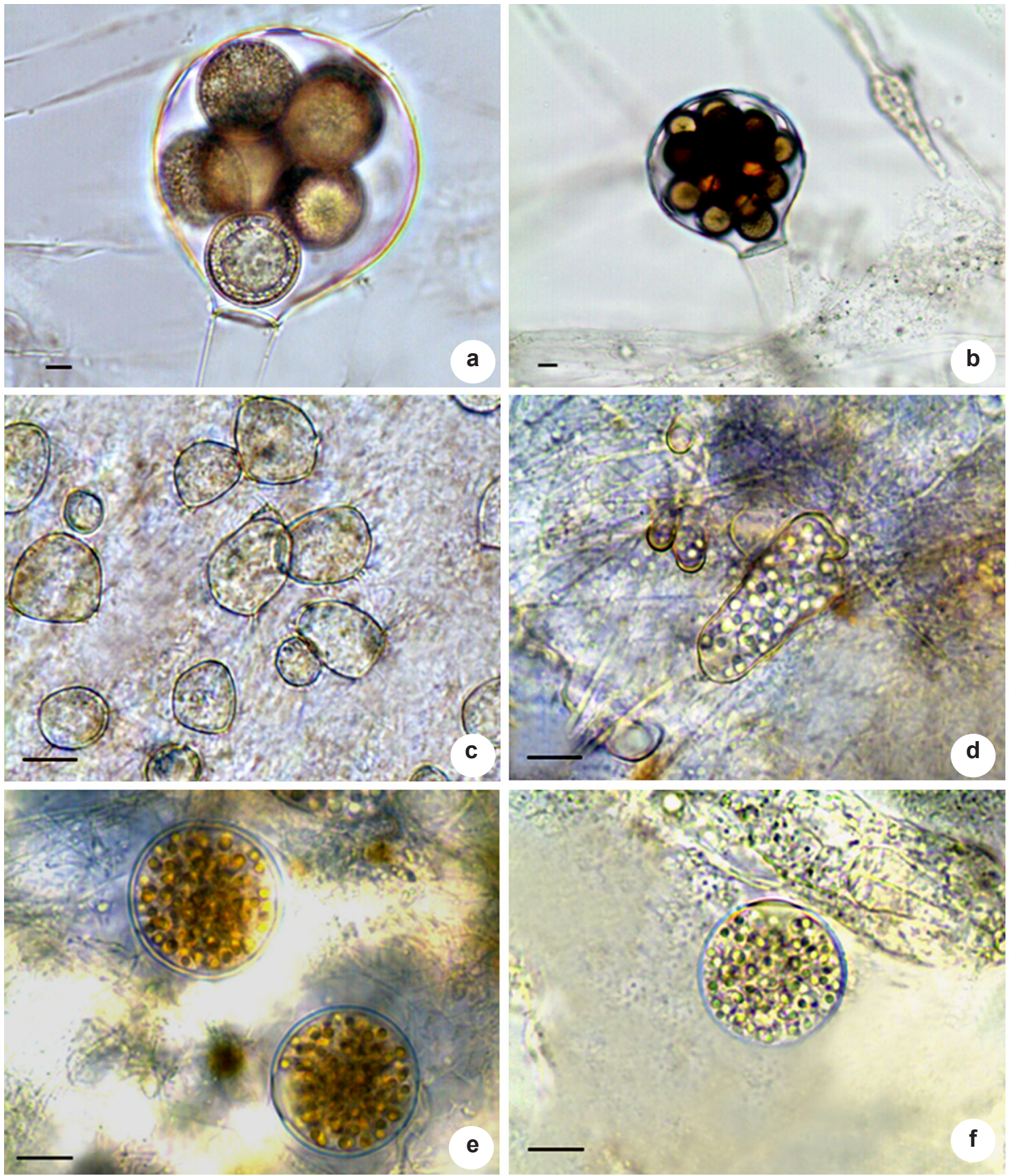

Figura 4 - Fungos zoospóricos da Reserva Biológica de Mogi Guaçu, São Paulo, Brasil. a-b. Saprolegnia ferax (Gruith.) Thuret - a. Oogônio com poros; b. Oogônio com oósporos subcêntricos. c. Catenophlyctis variabilis (Karling) Karling - Zoosporângios em ecdise de cobra. d. Chytriomyces appendiculatus Karling - Zoosporângio apendiculado. e. C. aureus Karling - Zoosporângios com opérculo e zoósporos. f. C. hyalinus Karling - Zoosporângio com opérculo e zoósporos. Barras: $10 \mu \mathrm{m}$.

Figure 4-Zoosporic fungi of the "Reserva Biológica de Mogi Guaçu", São Paulo State, Brazil. a-b. Saprolegnia ferax (Gruith.) Thuret - a. Oogonium with pores. b. Oogonium with subcentric oospores. c. Catenophlyctis variabilis (Karling) Karling - Zoosporangia in sn ake skin. d. Chytriomyces appendiculatus Karling - Appendiculated zoosporangium. e. C. aureus Karling - Zoosporangia with operculum and zoospores. f. C. hyalinus Karling - Zoosporangium with operculum and zoospores. Bars: $10 \mu \mathrm{m}$. 
Ocorre no Amazonas, Piauí, Pernambuco, Minas Gerais, São Paulo.

A espécie se caracteriza pela presença de zoosporângios inoperculados de tamanhos e formas muito variáveis, organizados radialmente em um rizomicélio muito ramificado, o que foi verificado nos espécimes isolados, concordando com a descrição original de Karling (1965). Neste estudo, a espécie apresentou crescimento saprofítico restrito a substrato queratinoso, ecdise de cobra, corroborando as citações de Karling (1946, 1947a), Milanez (1984) e Pires-Zottarelli \& Rocha (2007), entretanto, Karling (1965) também cita seu crescimento em substrato celulósico. A primeira ocorrência para o Brasil é de Karling (1947a), sob a combinação Phlyctorhiza variabilis, crescendo saprofiticamente em tecidos queratinizados de insetos mortos, coletados em Manaus (AM).

\section{CHYTRIDIOMYCOTA CHYTRIDIALES \\ CHYTRIDIACEAE}

Chytriomyces appendiculatus Karling, Bull. Torrey Bot. Club 74: 335. $1947 . \quad$ Fig. 4d

Descrição: Nascimento \& Pires-Zottarelli (2009).

Material examinado: Reserva Biológica de Mogi Guaçu, amostra de água das áreas "A" e "B", 28.I.2008, 28.IV.2008, 28.VII.2008 e 20.X.2008, e de solo das áreas "A" e "B", 28.I.2008 e 28.VII.2008, em exoesqueleto de camarão, C.A. Nascimento (SP 393727).

Ocorre em Minas Gerais, São Paulo.

A espécie se caracteriza pela presença de zoosporângios operculados, não apofisados e apendiculados, características observadas nos espécimes isolados, concordando com a descrição original de Karling (1947b). A primeira citação de Chytriomyces appendiculatus para o Brasil é referente ao material isolado de amostras de água e solo, coletadas em áreas de Cerrado no estado de São Paulo (Pires-Zottarelli \& Rocha 2007).

Chytriomyces aureus Karling, Am. J. Bot. 32: 363. 1945.

Fig. $4 \mathrm{e}$

Descrição: Nascimento \& Pires-Zottarelli (2009).

Material examinado: Reserva Biológica de Mogi Guaçu, amostras de água da área "A", 28.I.2008, em exoesqueleto de camarão, C.A. Nascimento (SP 393739).

Ocorre no Amazonas, Piauí, São Paulo.

A presença de zoosporângios operculados, apofísados ou não, e zoósporos com uma típica gotícula lipídica dourada são características marcantes da espécie, as quais foram facilmente verificadas nos espécimes examinados neste estudo. Foi isolada apenas em substrato quitinoso, exoesqueleto de camarão, como relatado por Karling (1945a) e Pires-Zottarelli \& Rocha (2007). Originalmente, a espécie foi isolada de substrato quitinoso em Flores Nabuco (AM) (Karling 1945a), porém, Sparrow Jr. (1960) também a relata em substrato celulósico (epiderme de cebola). Chytriomyces aureus é morfologicamente semelhante a C. hyalinus Karling, porém, C. aureus é facilmente diferenciado pela coloração dourada da gotícula lipídica do zoósporo, que é hialina, sem coloração, em C. hyalinus.

Chytriomyces hyalinus Karling, Am. J. Bot. 32: 363. 1945.

Fig. $4 \mathrm{f}$

Descrição: Nascimento \& Pires-Zottarelli (2009).

Material examinado: Reserva Biológica de Mogi Guaçu, amostras de água das áreas "A" e "B", 28.I.2008, 28.IV.2008 e 20.X.2008, em exoesqueleto de camarão e ecdise de cobra, C.A. Nascimento (SP 393738).

Ocorre no Amazonas, Piauí, Minas Gerais, São Paulo.

A presença de zoosporângios operculados, apofisados ou não, e zoósporos com uma gotícula lipídica hialina caracterizam esta espécie. Foi isolada em substrato quitinoso, exoesqueleto de camarão, concordando com Karling (1945a) e Pires-Zottarelli \& Rocha (2007), além de substrato queratinoso e ecdise de cobra. Entretanto, Sparrow Jr. (1960) menciona sua ocorrência em substrato celulósico e epiderme de cebola. A espécie foi originalmente descrita por Karling (1945a), isolada de amostras iscadas com substrato quitinoso, coletadas em Flores Nabuco (AM).

Chytriomyces spinosus Fay, Mycologia 39: 152. 1947.

Fig. 5a

Descrição: Nascimento \& Pires-Zottarelli (2009).

Material examinado: Reserva Biológica de Mogi Guaçu, amostras de água das áreas "A" e "B", 28.I.2008, 28.IV.2008, 28.VII.2008 e 20.X.2008, em epiderme de cebola e palha de milho, C.A. Nascimento (SP 393736).

Ocorre no Amazonas, Piauí, São Paulo.

A principal característica da espécie é a presença de zoosporângios operculados, não apofisados, apresentando ornamentações em forma de espinhos agudos e não bifurcados, que 
foi facilmente visualizada nos espécimes isolados. Apresentou crescimento apenas em substrato celulósico, epiderme de cebola e palha de milho, concordando com a descrição original de Fay (1947). Pires-Zottarelli \& Rocha (2007) citam a presença de espinhos bifurcados na parede do zoosporângio, porém esta característica não foi observada nos espécimes isolados neste estudo. Chytriomyces spinosus foi isolada pela primeira vez no Brasil por I.L. Silva, em amostras de água e solo coletadas em Manaus (AM) (Milanez et al. 2007).

Karlingiomyces dubius (Karling) Sparrow Jr., Aquatic Phycomycetes, p. 561. $1960 . \quad$ Fig. 5b

Basiônimo: Karlingia dubia Karling, Mycologia 41: 513. 1949.

Descrição: Pires-Zottarelli \& Rocha (2007), como Karlingia dubia Karling.

Material examinado: Reserva Biológica de Mogi Guaçu, amostras de água da área "A", 28.VII.2008, em epiderme de cebola e palha de milho, C.A. Nascimento (SP 393744).

Ocorre em São Paulo.

Esta espécie é caracterizada, principalmente, pela presença de esporos de resistência com parede lisa a levemente verrucosa ou ondulada, normalmente castanho-escuros, sendo estas características facilmente observadas nos espécimes isolados, concordando com a descrição original de Karling (1949). Entretanto, o autor mencionou crescimento em substrato quitinoso, e neste estudo a espécie foi observada apenas em substrato celulósico. Foi descrita pela primeira vez no Brasil por C.L.A. Pires-Zottarelli, em amostras de água e solo coletadas em Cubatão (SP) e iscadas com palha de milho (SchoenleinCrusius et al. 2006).

Karlingiomyces granulatus (Karling) Sparrow Jr., Aquatic Phycomycetes, p. 563. $1960 . \quad$ Fig. 5c

Basiônimo: Karlingia granulata Karling, Mycologia 39: 57.1947.

Descrição: Nascimento \& Pires-Zottarelli (2010), como Karlingia granulata Karling.

Material examinado: Reserva Biológica de Mogi Guaçu, amostras de água das áreas "A" e "B", 28.I.2008 e 28.IV.2008, e de solo das áreas "A" e "B", 28.I.2008, 28.IV.2008, 28.VII.2008 e 20.X.2008, em epiderme de cebola, palha de milho e celofane, C.A. Nascimento (SP 393723).

Ocorre no Amazonas, Rondônia, Minas Gerais, São Paulo.
A ocorrência de zoosporângios exo e/ou endoperculados, parede lisa, mas tornando-se enrugada na maturidade, com coloração de hialina a acinzentada, rizóides extensivos e geralmente constritos, são características marcantes desta espécie. A espécie apresentou crescimento em substratos celulósicos, concordando com Karling (1947b), Dogma Jr. (1974a) e Rocha \& PiresZottarelli (2002), o que sugere a especificidade da espécie com este tipo de substrato. A primeira citação desta espécie no Brasil é de Karling (1947b), que a isolou de amostras de solo coletadas em São Carlos (RO).

Phlyctochytrium aureliae Ajello, Mycologia 37: 110. 1945.

Fig. $5 \mathrm{~d}$

Descrição: Nascimento \& Pires-Zottarelli (2009).

Material examinado: Reserva Biológica de Mogi Guaçu, amostras de solo das áreas "A" e "B", 28.I.2008, 28.VII.2008 e 20.X.2008, em epiderme de cebola, grãos de pólen e ecdise de cobra, C.A. Nascimento (SP 393726).

Ocorre em São Paulo.

Phlyctochytrium aureliae se caracteriza pelos zoosporângios inoperculados, com apófise composta, apresentando ornamentações em forma de espinhos bifurcados, distribuídos de forma desorganizada em toda a superfície do zoosporângio, facilmente observados nos espécimes examinados. Foi isolada de substrato queratinoso (ecdise de cobra) e celulósico (epiderme de cebola e grãos de pólen), concordando com Ajello (1945) e Sparrow Jr. \& Lange (1976). A primeira observação da espécie no Brasil é de A.I. Milanez, que a isolou de amostras de solo, coletadas em Limeira, Pedrinhas e Riacho Grande (SP) (Pires-Zottarelli $\&$ Gomes 2007).

Rhizidium verrucosum Karling, Am. J. Bot. 31: 255. 1944.

Fig. 5e

Descrição: Pires-Zottarelli \& Gomes (2007). Material examinado: Reserva Biológica de Mogi Guaçu, amostras de solo das áreas "A" " "B", 28.I.2008, 28.VII.2008 e 20.X.2008, em exoesqueleto de camarão e ecdise de cobra, C.A. Nascimento (SP 393733).

Ocorre em Rondônia, São Paulo.

A espécie se caracteriza, principalmente, pelas ornamentações verrucosas presentes na parede dos zoosporângios, as quais foram observadas nos isolados, concordando com a descrição original de Karling (1944a), que a isolou de amostra de água coletadas em São Carlos (RO). 

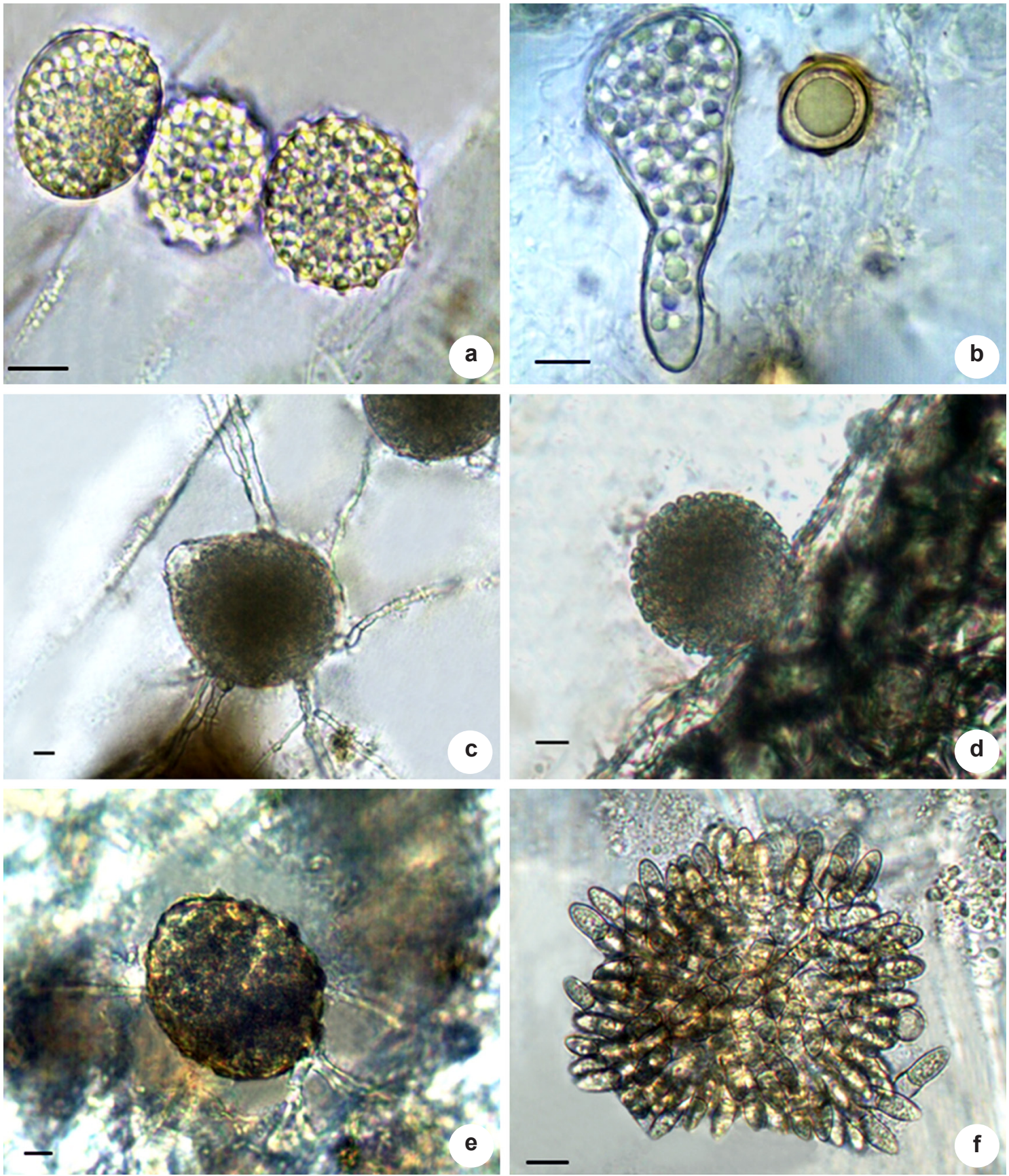

Figura 5 - Fungos zoospóricos da Reserva Biológica de Mogi Guaçu, São Paulo, Brasil. a. C Chytriomyces spinosus Fay - Zoosporângios ornamentados. b. Karlingiomyces dubius (Karling) Sparrow Jr. - Zoosporângio e esporo de resistência em exoesqueleto de camarão. c. K. granulatus (Karling) Sparrow Jr.-Zoosporângio com rizóides constrictos. d. Phlyctochytrium aureliae Ajello - Zoosporângio com ornamentações em ecdise de cobra. e. Rhizidium verrucosum Karling - Zoosporângios. f. Septosperma rhizophydii Whiffen ex W.H. Blackwell \& M. J. Powell - Zoosporângios e esporos de resistência em Rhizophydium sp. Barras: $10 \mu \mathrm{m}$.

Figure 5 - Zoosporic fungi of the "Reserva Biológica de Mogi Guaçu", São Paulo State, Brazil. a. Chytriomyces spinosus Fay Ornamented zoosporangia. b. Karlingiomyces dubius (Karling) Sparrow Jr. - Zoosporangium and resting spore in exoskeleton of shrimp. c. K. granulatus (Karling) Sparrow Jr. - Zoosporangium with constricted rhizoids. d. Phlyctochytrium aureliae Ajello - Ornamented zoosporangium in snake skin. e. Rhizidium verrucosum Karling - Empty zoosporangia .f. Septosperma rhizophydii Whiffen ex W.H. Blackwell \& M. J. Powell - Zoosporangia and resting spores in Rhizophydium sp. Bars: $10 \mu \mathrm{m}$. 
Septosperma rhizophydii Whiffen ex W.H. Blackw. \& M.J. Powell, Mycotaxon 42: 45. 1991. Fig. 5f

Descrição: Nascimento \& Pires-Zottarelli (2009).

Material examinado: Reserva Biológica de Mogi Guaçu, amostra de solo das áreas "A" e "B", 28.I.2008 e 20.X.2008, parasita em Rhizophydium sp., C.A. Nascimento (SP 393740).

Ocorre em São Paulo.

A espécie se caracteriza pelo comportamento parasítico, com abundante produção de esporos de resistência cilíndricos, apresentando uma conspícua região fértil localizada na parte apical do esporo, preenchida com várias gotículas lipídicas, sendo estas características observadas nos espécimes isolados, concordando com a descrição original de Whiffen (1942). Foi observada parasitando somente zoosporângios de Rhizophydium sp., no entanto, outros hospedeiros são citados em literatura, como Rhizophydium macrosporum Karling, Rhizidium richmondense Willoughby, Rhizophlyctis sp. e Rhizidiomyces apophysatus Zopf (Whiffen 1942, Willoughby 1965, Seymour 1971). Foi relatada pela primeira vez no Brasil por Milanez (1974), que a isolou como parasita de zoosporângios de Rhizophydium sp. de amostras de solo iscadas com grãos de pólen, coletadas em São Paulo (SP).

\section{CLADOCHYTRIACEAE}

Cladochytrium replicatum Karling, Amer. J. Bot. 18: 538. 1931.

Fig. 6a-b

Descrição: Nascimento \& Pires-Zottarelli (2009).

Material examinado: Reserva Biológica de Mogi Guaçu, amostras de água das áreas "A" e "B", 28.I.2008, 28.IV.2008, 28.VII.2008 e 20.X.2008, em epiderme de cebola, palha de milho e celofane, C.A. Nascimento (SP 393732).

Ocorre no Amazonas, Piauí, Ceará, Pernambuco, Acre, Rondônia, Mato Grosso, Minas Gerais, São Paulo.

A espécie se caracteriza pela presença de um rizomicélio delicado, ramificado, com células turbinadas e septadas, zoosporângios inoperculados, onde são formados zoósporos com uma típica gotícula lipídica dourada, e esporos de resistência com um glóbulo lipídico de coloração dourada, o que foi observado nos espécimes isolados, estando de acordo com a descrição original de Karling (1931). A espécie foi isolada pela primeira vez no Brasil por Karling (1945b), de amostras de água coletadas nos estados do Acre, Mato Grosso, Amazonas e Ceará, em cidades não especificadas.
Cladochytrium tenue Nowakowski, Cohn. Beitr. Biol. Pflanzen 2: $92.1876 . \quad$ Fig. 6c Descrição: Nascimento \& Pires-Zottarelli (2009).

Material examinado: Reserva Biológica de Mogi Guaçu, amostras de água das áreas "A" e "B", 28.I.2008, 28.IV.2008, 28.VII.2008 e 20.X.2008, e de solo das áreas "A" e "B", 28.I.2008, 28.VII.2008 e 20.X.2008 em epiderme de cebola, C.A. Nascimento (SP 393728).

Ocorre no Amazonas, Piauí, Rondônia, Mato Grosso, São Paulo.

A presença de um rizomicélio extensivo, ramificado, com células turbinadas intercalares e esporos de resistência com um glóbulo lipídico de coloração hialina, são características marcantes da espécie, as quais foram observadas nos espécimes isolados. A primeira citação da espécie no Brasil é de Karling (1945b), que a isolou de amostras de água e solo, iscadas com substratos celulósicos, epiderme de cebola e palha de milho, coletadas em São Carlos e Porto Velho (RO) e em Manaus (AM).

Nowakowskiella elegans (Nowak.) Schroeter, Engler and Prantl, Naturlichen Pflanzenfam. 1: 82. 1892/1893.

Fig. 6d

Basiônimo: Cladochytrium elegans Nowak., pro parte, in Cohn, Beitr. Biol. Pflanzen 2: 95. 1876.

Descrição: Nascimento \& Pires-Zottarelli (2009).

Material examinado: Reserva Biológica de Mogi Guaçu, amostras de água das áreas "A" e "B", 28.VII.2008, em palha de milho, C.A. Nascimento (SP 3937230).

Ocorre no Amazonas, Piauí, Paraíba, Pernambuco, Rondônia, São Paulo.

A espécie se caracteriza pela presença de um rizomicélio extensivo e ramificado, com zoosporângios operculados, apofisados ou não, facilmente verificados nos espécimes examinados, concordando com Sparrow Jr. (1960) e Karling (1977). A primeira citação no Brasil é de Karling (1944b), que a isolou de amostras de água e solo coletadas em São Carlos (RO).

Polychytrium aggregatum Ajello, Mycologia 34: 442. 1942.

Fig. 6e-f

Descrição: Pires-Zottarelli \& Gomes (2007). Material examinado: Reserva Biológica de Mogi Guaçu, amostras de água das áreas "A" e "B", 28.I.2008, 28.IV.2008, 28.VII.2008 e 20.X.2008, em exoesqueleto de camarão, C.A. Nascimento (SP 393731).

Ocorre no Amazonas, Piauí, São Paulo.

Zoosporângios inoperculados e prolíferos, terminais ou intercalares, formando agregados 

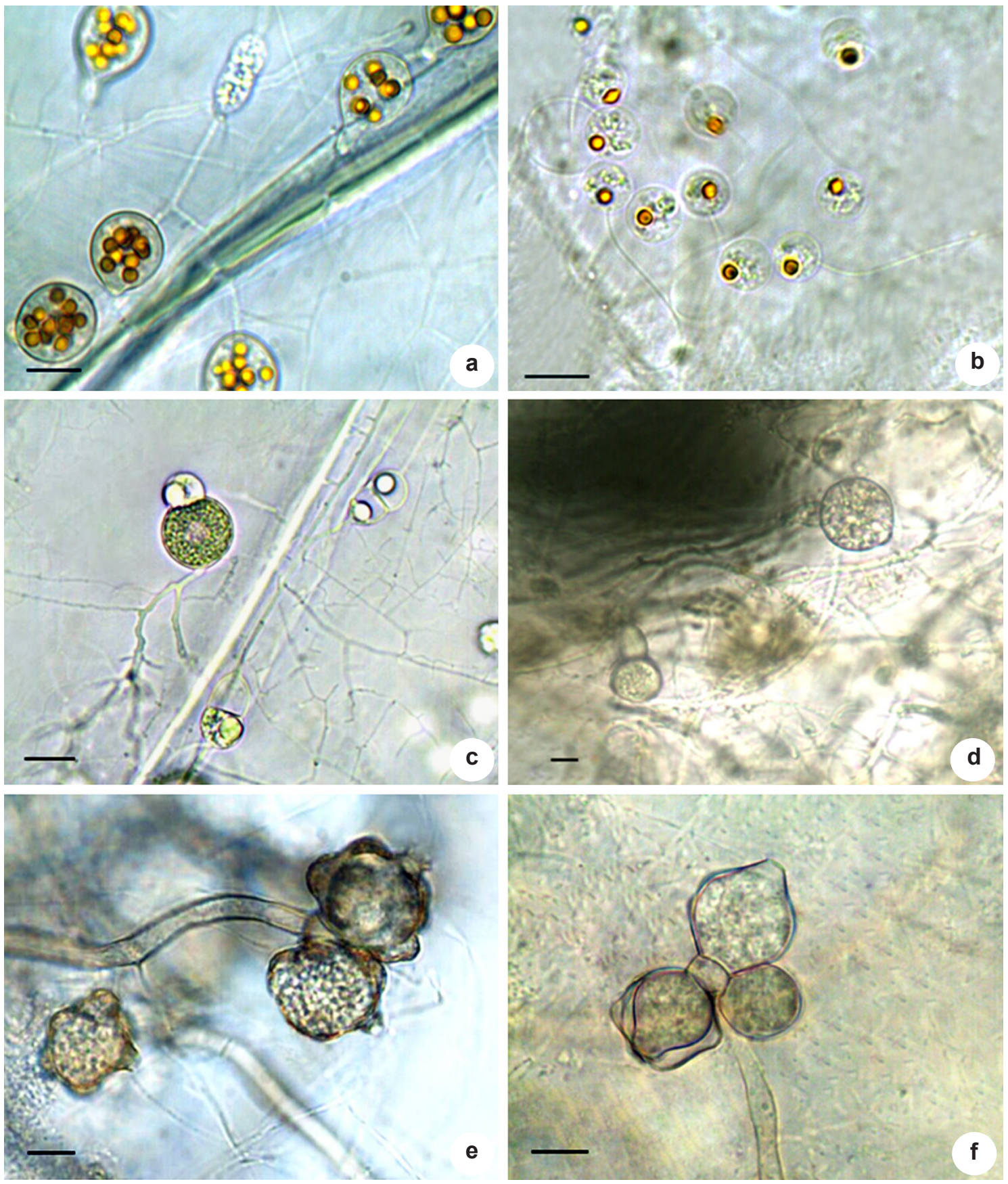

Figura 6 - Fungos zoospóricos da Reserva Biológica de Mogi Guaçu, São Paulo, Brasil. a-b. Cladochytrium replicatum Karling - a. Talo policêntrico com zoosporângios e células turbinadas; b. Zoósporos. c. C. tenue Karling - Talo policêntrico com esporos de resistência apofisados e células turbinadas. d. Nowakowskiella elegans (Nowak.) Schröeter - Zoosporângios apofisados. e-f. Polychytrium agregatum Ajello - e. Zoosporângios; f. Zoosporângio com proliferação interna. Barras: $10 \mu \mathrm{m}$.

Figure 6-Zoosporic fungi of the "Reserva Biológica de Mogi Guaçu”, São Paulo State, Brazil. a-b. Cladochytrium replicatum Karling -a. Polycentric thallus with zoosporangia and turbinate cells; b. Zoospores. c. C. tenue Karling - Polycentric thallus with apophysated resting spores and turbinate cells. d. Nowakowskiella elegans (Nowak.) Schröeter - Zoosporangia with apophyses. e-f. Polychytrium agregatum Ajello - e. Zoosporangia; f. Zoosporangia with internal proliferation. Bars: $10 \mu \mathrm{m}$. 
em um rizomicélio ramificado, parede lisa ou ornamentações tuberculadas e/ou papiladas, são características da espécie, tendo sido observadas nos isolados deste estudo, concordando com a descrição original de Ajello (1942). Até o momento, é a única espécie deste gênero. para o mundo. Foi citada pela primeira vez no Brasil por Ajello (1948), a partir de amostras coletadas por J.S. Karling, em 1943, em Manaus (AM) (Milanez et al. 2007).

Septochytrium willoughbyi Dogma Jr., Nova Hedwigia 24: 367. 1973.

Fig. 7a-b

Descrição: Nascimento \& Pires-Zottarelli (2009).

Material examinado: Reserva Biológica de Mogi Guaçu, amostras de solo das áreas "A" e "B", 28.I.2008, 28.IV.2008, 28.VII.2008 e 20.X.2008, em palha de milho e epiderme de cebola, C.A. Nascimento (SP 393724).

Ocorre no Piauí, Rondônia, Minas Gerais, São Paulo.

A presença de um rizomicélio extensivo e ramificado, no qual são formados zoosporângios operculados, apresentando um típico aspecto rugoso na maturidade, que se torna bem mais evidente após a liberação dos zoósporos, e esporos de resistência com protuberâncias na parede, são características marcantes desta espécie, as quais foram frequentemente observadas nos espécimes isolados. A espécie foi descrita pela primeira vez no Brasil por Dogma Jr. (1973), isolada de amostras de solo, iscadas com substratos celulósicos, epiderme de cebola e celofane, coletadas em Jaci Paraná (RO).

\section{ENDOCHYTRIACEAE}

Diplophlyctis sarcoptoides (H. E. Petersen) Dogma Jr., Nova Hedwigia 25: 122. 1974.

Fig. 7c-d

Basiônimo: Asterophlyctis sarcoptoides H. E. Petersen, J. Bot. 17: 218. 1903.

Descrição: Nascimento \& Pires-Zottarelli (2009).

Material examinado: Reserva Biológica de Mogi Guaçu, amostras de água das áreas “A” e "B”, 28.I.2008, 28.IV.2008, 28.VII.2008 e 20.X.2008, em exoesqueleto de camarão, C.A. Nascimento (SP 393737).

Ocorre no Amazonas, Rondônia, Minas Gerais, São Paulo.

Esta espécie se caracteriza pela formação de zoosporângios inoperculados e apofisados, com ornamentações tuberculadas, espinhosas ou papiladas, e esporos de resistência apofisados, apresentando ornamentações semelhantes às do zoosporângio, facilmente visualizadas nos espécimes isolados, que foram observados crescendo em substrato quitinoso, exoesqueleto de camarão, o que concorda com Dogma Jr. (1974b) e Rocha \& Pires-Zottarelli (2002). A primeira citação deste gênero no Brasil, com o nome Asterophlyctis, é de J.S. Karling, em 1945, no entanto, a espécie A. sarcoptoides só foi referida por Antikajian, em 1949, a partir do espécime fornecido por J.S. Karling, isolado de amostras de solo coletadas em São Carlos (RO) (Milanez 1984). Baseado em observações do desenvolvimento do talo de A. sarcoptoides, Dogma Jr. (1974b) transferiu a espécie para o gênero Diplophlyctis.

Entophlyctis luteolus Longcore, Mycologia 87: 27. 1995.

Fig. 7e-f

Descrição e ilustrações: Pires-Zottarelli et al. (2007b).

Material examinado: Reserva Biológica de Mogi Guaçu, amostras de água das áreas "A" e "B", 28.I.2008, 28.IV.2008 e 20.X.2008, e de solo das áreas "A" e "B", 28.I.2008, 28.IV.2008, 28.VII.2008 e 20.X.2008, em epiderme de cebola e palha de milho, C.A. Nascimento (SP 393735).

Ocorre em São Paulo.

A presença de cisto no zoosporângio e esporos de resistência, que possuem parede interna e/ou externa lisa ou irregular, apresentando uma típica coloração amarelada, são as principais características da espécie, as quais foram frequentemente observadas nos espécimes isolados. Foi descrita pela primeira vez no Brasil por PiresZottarelli et al. (2007b), isolada de amostras de água e solo iscadas com substratos celulósicos, epiderme de cebola e palha-de-milho, coletadas em Santo André e São Paulo (SP).

\section{MONOBLEPHARIDALES GONAPODYACEAE}

Gonapodya prolifera (Cornu) A. Fisch. Rabenhorst, Kryptogamen - Fl., 1: 382. $1892 . \quad$ Fig. 8a

Basiônimo: Monoblepharis prolifera Cornu, Ann. Sci. Nat., Bot. 15: 16. 1877.

Descrição: Pires-Zottarelli \& Gomes (2007). Material examinado: Reserva Biológica de Mogi Guaçu, amostras de água da área "B", 20.X.2008, em semente de Sorghum sp., C.A. Nascimento (SP 393741).

Ocorre no Amazonas, Piauí, Minas Gerais, São Paulo.

A ocorrência em pústulas esbranquiçadas, apresentando micélio com hifas regulares, 

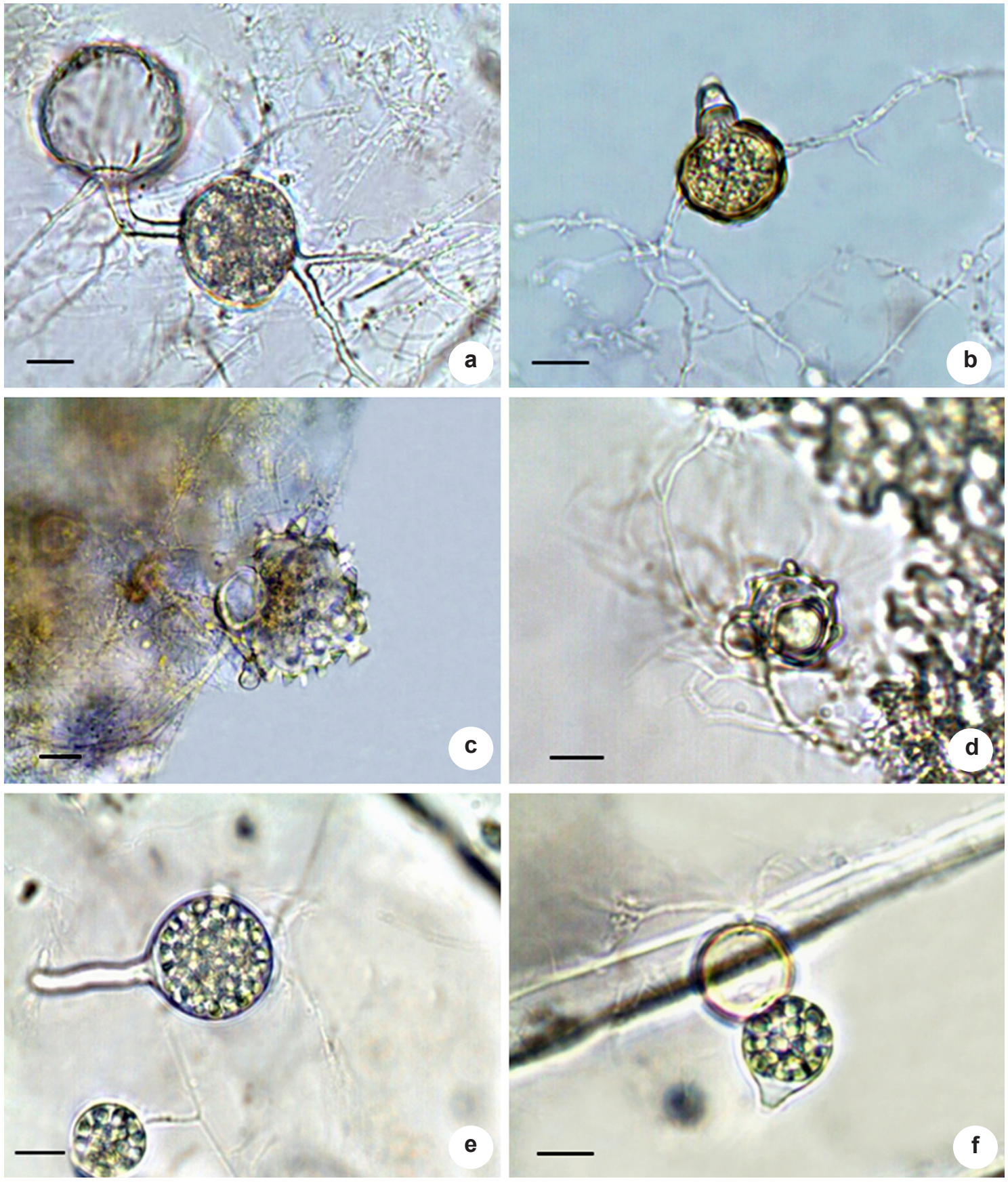

Figura 7 - Fungos zoospóricos da Reserva Biológica de Mogi Guaçu, São Paulo, Brasil. a-b. Septochytrium willoughbyi Dogma Jr. - a. Zoosporângio vazio evidenciando aspecto enrugado da parede; b. Esporo de resistência. c-d. Diplophlyctis sarcoptoides (H.E. Petersen) Dogma Jr. - c. Zoosporângio apofisado; d. Esporo de resistência. e-f. Entophlyctis luteolus Longcore-e. Zoosporângios em epiderme de cebola; f. Germinação do esporo de resistência. Barras: $10 \mu \mathrm{m}$.

Figure 7 - Zoosporic fungi of the "Reserva Biológica de Mogi Guaçu", São Paulo State, Brazil. a-b. Septochytrium willoughbyi Dogma Jr. - a. Empty zoosporangium with furrowed wall; b. Resting spore. c-d. Diplophlyctis sarcoptoides (H.E. Petersen) Dogma Jr. - c. Zoosporangium with apophyses; d. Resting spore. e-f. Entophlyctis luteolus Longcore - e. Zoosporangia on onion skin; f. Resting spore germination. Bars: $10 \mu \mathrm{m}$. 
formando pseudo-septos que as divide em segmentos clavados, e zoosporângios abundantes elíptico-alongados e com proliferação interna são características típicas desta espécie que foram visualizadas nos espécimes isolados neste estudo, concordando com a descrição de Karling (1977).

\section{RHIZOPHLYCTIDALES RHIZOPLHYCTIDACEAE}

Rhizophlyctis rosea (De Bary \& Woronin) A. Fish, Rabenhorst's Kryptogamen-Fl. 1: 122. 1891.

Fig. $8 b$

Basiônimo: Chytridium roseum de Bary \& Woronin, Ber. Verh. Naturf. Ges. Freiburg 3: 52. 1865.

Descrição: Nascimento \& Pires-Zottarelli (2010), como Karlingia rosea (de Bary \& Woronin) Karling.

Material examinado: Reserva Biológica de Mogi Guaçu, amostra de água da área "A", 28.VII.2008, e amostras de solo das áreas "A" e "B", 28.I.2008, 28.IV.2008, 28.VII.2008 e 20.X.2008, em epiderme de cebola, palha de milho e celofane, C.A. Nascimento (SP 393730).

Ocorre no Amazonas, Piauí, Maranhão, Acre, Rondônia, Goiás, Mato Grosso do Sul, Paraíba, Alagoas, Pernambuco, Bahia, Minas Gerais, Rio de Janeiro, São Paulo, Paraná, Santa Catarina, Rio Grande do Sul.

Rhizophlyctis rosea se caracteriza, principalmente, pela formação de zoosporângios endoperculados, com conteúdo variando de uma coloração rósea, no início do desenvolvimento, a marrom-avermelhada na maturidade, sendo estas características facilmente verificadas nos espécimes isolados. Na literatura, algumas divergências quanto à posição desta espécie em nível genérico foram abordadas. Em 1856, A. de Bary e M. Woronin descreveram esta espécie sob a combinação de Chytridium roseum, caracterizada principalmente pela presença de zoosporângios inoperculados. Posteriormente, em 1892, A. Fischer propôs Rhizophlyctis como um novo genêro para englobar espécies que apresentavam morfologia semelhante a esta, e sinonimizou C. roseum com Rhizophlyctis rosea (Johanson 1944). A partir de novas observações do desenvolvimento do zoosporângio e da liberação dos zoósporos desta espécie, Johanson (1944) conclui que nela ocorria a formação de opérculo e, portanto, não poderia permanecer no gênero inoperculado Rhizophlyctis. O autor então estabeleceu o novo gênero Karlingia para abranger espécies com zoosporângios exo e/ou endoperculados e sinonimizou $R$. rosea com Karlingia rosea. Sparrow
Jr. (1960) considerou a endoperculação como um caráter genericamente inválido e sinonimizou Karlingia com Rhizophlyctis, transferindo todas as espécies endoperculadas de Karlingia para este gênero e as exoperculadas para Karlingiomyces, um novo gênero por ele estabelecido. Por sua vez, Dogma Jr. (1974a) aceitou tanto Karlingia, com espécies endoperculadas, como Karlingiomyces com exoperculadas (Sparrow Jr. 1960, Dogma Jr. 1974a, Karling 1977). Interpretando que o gênero inclui espécies endo e/ou exoperculadas, Karling (1977) sinonimizou Karlingiomyces com Karlingia. Recentemente, Blackwell et al. (2004) abordaram todas as discussões envolvendo este gênero e concordaram com a visão taxonômica de Sparrow Jr. (1960), que também é aceita no presente estudo.

\section{RHIZOPHYDIALES RHIZOPHYDIACEAE}

Rhizophydium coronum Hanson, Torreya 44: 31. 1944.

Fig. $8 \mathrm{c}-\mathrm{d}$

Descrição: Pires-Zottarelli \& Gomes (2007). Material examinado: Reserva Biológica de Mogi Guaçu, amostras de solo das áreas "A" e "B", 28.I.2008, 28.IV.2008, 28.VII.2008 e 20.X.2008, em epiderme de cebola, palha de milho, celofane e ecdise de cobra, C.A. Nascimento (SP 393722).

Ocorre em São Paulo.

A espécie se caracteriza pela presença de zoosporângios com halos concêntricos e que não se deliquescem antes da liberação dos zoósporos, os quais foram verificados nos espécimes examinados, estando de acordo com a descrição original de Hanson (1944). Foi mencionada pela primeira vez no Brasil por T. Booth, em 1979, de amostras de solo de duna em Cananéia (SP) (Milanez et al. 2007).

Rhizophydium elyense Sparrow Jr., Trans. Brit. Mycol. Soc. 40: 525. 1957.

Fig. 8e

Descrição: Nascimento \& Pires-Zottarelli (2009).

Material examinado: Reserva Biológica de Mogi Guaçu, amostras de água da área "B", 28.IV.2008 e 20.X.2008, e de solo das áreas "A" e "B", 28.I.2008, 28.IV.2008, 28.VII.2008 e 20.X.2008, em epiderme de cebola e ecdise de cobra, C.A. Nascimento (SP 393725).

Ocorre no Amazonas, Piauí, São Paulo.

$\mathrm{O}$ aspecto angular do zoosporângio na maturidade, resultado da formação de várias papilas, e a presença de rizóides delicados e ramificados, saindo de um eixo principal, são características marcantes desta espécie, as quais foram frequentemente observadas nos espécimes 

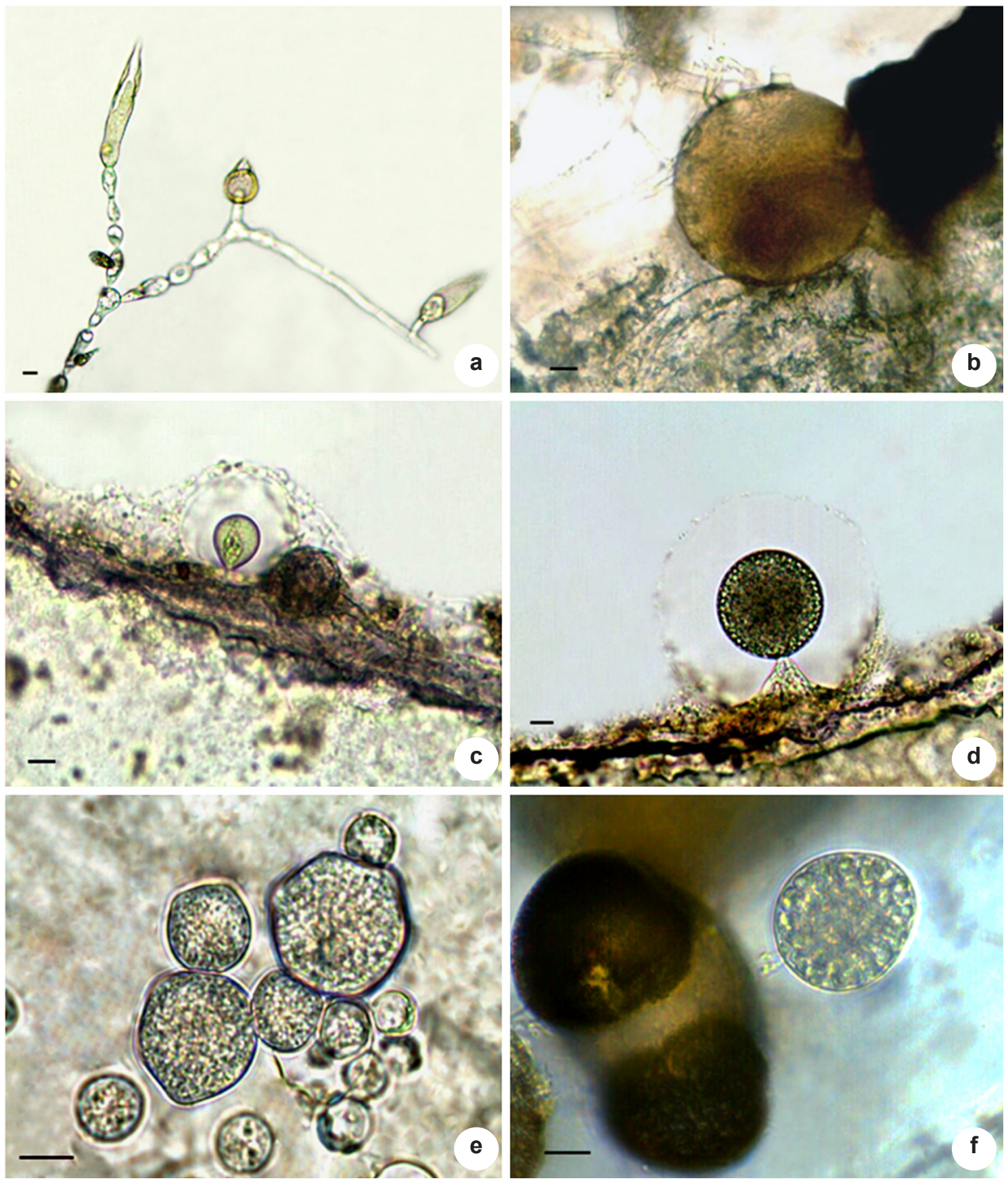

Figura 8 - Fungos zoospóricos da Reserva Biológica de Mogi Guaçu, São Paulo, Brasil. a. Gonapodya prolifera (Cornu) A. Fisch. - Zoosporângios com proliferação interna. b. Rhizophlyctis rosea (de Bary \& Woronin) A. Fisch. -Zoosporângios com tubos de liberação e rizóides. c-d. Rhizophydium coronum A.M. Hanson - c. Zoosporângio jovem com halo concêntrico; d. Zoosporângio adulto com halo concêntrico. e. Rhizophydium elyense Sparrow Jr. - Zoosporângios angulares. f. Rhizophydium stipitatum Sparrow Jr. - Zoosporângio com pedúnculo extramatrical. Barras: $10 \mu \mathrm{m}$.

Figure 8 - Zoosporic fungi of the "Reserva Biológica de Mogi Guaçu", São Paulo State, Brazil. a. Gonapodya prolifera (Cornu) A. Fisch. - Zoosporangia with internal proliferation. b. Rhizophlyctis rosea (de Bary \& Woronin) A. Fisch. - Zoosporangia with exit tubes and rhizoids. c-d. Rhizophydium coronum A.M. Hanson - c. Young zoosporangia with concentric halo; d. Mature zoosporangium with concentric halo. e. Rhizophydium elyense Sparrow Jr. - Angular zoosporangia. f. Rhizophydium stipitatum Sparrow Jr. - Zoosporangium with extramatical stalk. Bars: $10 \mu \mathrm{m}$. 
examinados, concordando com a descrição original de Sparrow Jr. (1957). Foi relatada pela primeira vez no Brasil por Pires-Zottarelli \& Milanez (1993), que a isolaram de amostras de água e solo, iscadas com palha de milho, grãos de pólen e ecdise de cobra, coletadas em Brotas-Itirapina (SP).

Rhizophydium stipitatum Sparrow Jr., Trans. Brit. Mycol. Soc. 40: 528. $1957 . \quad$ Fig. $8 f$

Descrição: Nascimento \& Pires-Zottarelli (2009).

Material examinado: Reserva Biológica de Mogi Guaçu, amostras de solo da área "A", 28.IV.2008, em grãos de pólen, C.A. Nascimento (SP 393729).

Ocorre no Amazonas, Piauí, São Paulo.

A formação de zoosporângios com um longo pedúnculo extramatrical no substrato é característica típica desta espécie, sendo observada nos espécimes isolados. Os espécimes estudados apresentaram comportamento saprofítico apenas em grãos de pólen, concordando com Milanez (1984), que a citou pela primeira vez para o Brasil, a partir de amostras de solo coletadas em Assis (SP).

Estudos anteriores reportaram 121 espécies de fungos zoospóricos de solo e/ou água em outras áreas de Cerrado no Brasil (Forzza et al. 2010). Dentre estes, embora não tenham abordado todo o grupo e realizado coletas restritas à área "A" da Reserva Biológica de Mogi Guaçu, Gomes et al. (2003) e Baptista et al. (2004) identificaram, respectivamente, 20 espécies de Saprolegniaceae e nove espécies de Pythium, indicando a expressiva diversidade local. O presente estudo contribuiu, significativamente, para o conhecimento da diversidade destes organismos na Reserva, pois, dentre as 38 espécies de fungos zoospóricos identificadas, 31 são primeiras citações para a área (Tab. 1).

Embora a maioria das espécies de fungos zoospóricos seja comum aos ambientes aquáticos e terrestres, algumas espécies podem ocorrer exclusivamente na água ou no solo (Willoughby 1961, Shearer et al. 2007). Ao longo do período de estudo, Olpidiopsis achlyae, Plectospira myriandra, Achlya proliferoides, A. radiosa, Saprolegnia ferax, Catenophlyctis variabilis, Chytriomyces aureus, $C$. hyalinus, C. spinosus, Karlingiomyces granulatus, Cladochytrium replicatum, Nowakowskiella elegans, Polychytrium aggregatum, Diplophlyctis sarcoptoides e Gonapodya prolifera ocorreram apenas na água, enquanto Brevilegnia minutandra, Phragmosporangium uniseriatum, Pythiopsis humphreyana, Phlyctochytrium aureliae, Rhizidium verrucosum, Septosperma rhizophydii, Septochytrium willoughbyi, Rhizophydium coronum e R. stipitatum foram exclusivas de solo. Por outro lado, Phythium vexans, Pythiogeton ramosum, Achlya dubia, A. orion, Chytriomyces appendiculatus, Karlingiomyces granulatus, Cladochytrium tenue, Entophlyctis luteolus, Rhizophlyctis rosea e Rhizophydium elyense ocorreram na água e no solo.

Comparando as áreas, o maior número de ocorrências (249) foi reportado na área "B", enquanto a área " $A$ " apresentou o maior número de espécies (34). Com relação às estações, o número de ocorrências foi mais pronunciado na estação seca (237) e o número de espécies foi igual nas duas estações (31) (Tab. 1). Trabalhos ecológicos realizados durante o período de estudo indicaram que as comunidades de fungos zoospóricos isolados na água e no solo apresentaram algumas modificações em sua estrutura, provavelmente influenciadas pelas características abióticas distintas de cada área ou estação (Nascimento et al. 2011a,b). Segundo estes estudos, na água, Achlya orion, Chytriomyces aureus e Karlingiomyces dubius foram restritas à área " $\mathrm{A}$ " que apresentou os menores valores de $\mathrm{pH}, \mathrm{Mg}$ e ferro total, enquanto Pythium vexans, Saprolegnia ferax e Rhizophydium elyense ocorreram apenas na área "B", na qual foram encontrados os maiores valores destas variáveis. Entre as estações Achlya orion, Chytriomyces aureus e Gonapodya prolifera ocorreram apenas na estação chuvosa, caracterizada pela presença dos maiores valores de temperatura, condutividade e cloreto, enquanto Achlya radiosa, Karlingiomyces dubius e Saprolegnia ferax associaram-se exclusivamente à estação seca que apresentou os maiores valores de oxigênio dissolvido. No solo, Achlya dubia, Leptolegniella keratinophila e Pythiogeton ramosum, exclusivas da área "A", foram relacionados aos maiores valores de $\mathrm{H}+\mathrm{Al}, \mathrm{CTC}$ e $\mathrm{P}$, enquanto, Leptolegnia subterranea, Pythiopsis humphreyana e Rhizophydium stipitatum ocorreram apenas na área "B", considerada mais preservada e com maior densidade de vegetação, associados aos maiores valores de $\mathrm{pH}$, $\mathrm{K}, \mathrm{Ca}, \mathrm{SB}, \mathrm{V} \%, \mathrm{Mg}, \mathrm{Mn}, \mathrm{Zn}$ e Pb. Considerando as estações, Achlya dubia, e Pythiogeton ramosum e Septosperma rhizophydii ocorreram apenas na estação chuvosa que apresentou os maiores valores de temperatura, $\mathrm{SB}, \mathrm{V} \%, \mathrm{Mg}, \mathrm{Mn}, \mathrm{Zn}$ e $\mathrm{Pb}$, enquanto Leptolegnia subterranea e Rhizophydium stipitatum foram associados aos menores valores destas variáveis na estação seca. 
Os resultados encontrados ampliam o conhecimento da ocorrência de fungos zoospóricos em áreas de Cerrado no estado de São Paulo e no Brasil, complementando estudos realizados anteriormente na Reserva Biológica de Mogi Guaçu.

\section{Agradecimentos}

Ao Conselho Nacional de Pesquisa e Desenvolvimento (CNPq), pela concessão de bolsa de doutorado à primeira autora e de produtividade em pesquisa à segunda autora. À Fundação Nacional de Amparo à Pesquisa do Estado de São Paulo (FAPESP, Processo 08/53146-4), pelo auxílio financeiro. Ao Instituto de Botânica de São Paulo, pela infra-estrutura oferecida para o desenvolvimento do trabalho.

\section{Referências}

Ajello, L. 1942. Polychytrium, a new cladochytriaceous genus. Mycologia 34: 442-451.

Ajello, L. 1945. Phlyctochytrium aureliae parasitized by Rhizophydium chytridiophagum. Mycologia 37: 109-119.

Ajello, L. 1948. A cytological and nutrition study of Polychytrium aggregatum, I: Citology. American Journal of Botany 35: 1-12.

Baptista, F.R.; Pires-Zottarelli, C.L.A.; Rocha, M. \& Milanez, A.I. 2004. O gênero Pythium Pringsheim de áreas de Cerrado no Estado de São Paulo, Brasil. Revista Brasileira de Botânica 27: 281-290.

Beneke, E.S. \& Rogers, L. 1962. Aquatic Phycomycetes isolated in the states of Minas Gerais, São Paulo and Paraná, Brazil. Rickia 1: 181-193.

Beneke, E.S. \& Rogers, L. 1970. Aquatic fungi of Parque Nacional de Itatiaia in the state of Rio de Janeiro. Rickia 5: 51-64.

Blackwell, W.H.; Letcher, P.M. \& Powell, M.J. 2004. Synopsis and systematic reconsideration of Karlingiomyces (Chytridiomycota). Mycotaxon 89: 259-276.

De Vuono, Y.S.; Barbosa, L.M. \& Batista, E.A. 1982. A Reserva Biológica de Moji-Guaçu. Silvicultura em São Paulo 16: 548-558.

Dogma Jr., I.J. 1973. Septochytrium willoughbyi, a new polycentric chytridiomycete with monocentric resting spore thalli. Nova Hedwigia 24: 367-377.

Dogma Jr., I.J. 1974a. Developmental and taxonomic studies of rhizophlyctoid fungi. Chytridiales, IV: Karlingia granulata, Karlingia spinosa, and Karlingiomyces dubius. Nova Hedwigia 25:91-105.

Dogma Jr., I.J. 1974b. Studies on chitinophilic Siphonaria, Asterophlyctis and Rhizoclosmatium, Chytridiales, II: Asterophlyctis sarcoptoides H.E. Petersen: a Diplophlyctis with a sexual phase. Nova Hedwigia 25: 1-50.
Durigan, G.; Baitello, J.B.; Franco, G.A.D.C. \& Siqueira, M.F. 2004. Plantas do cerrado paulista: imagem de uma paisagem ameaçada. Páginas \& Letras, São Paulo. 475p.

Fay, D.J. 1947. Chytriomyces spinosus nov. sp. Mycologia 39: 152-157.

Figueiredo, M.B. \& Pimentel, C.P.V. 1975. Métodos utilizados para conservação de fungos na Micoteca da Seção de Micologia Fitopatológica do Instituto Biológico. Summa Phytopathologica 1: 299-302.

Forzza, R.C.; Leitman, P.M.; Costa, A.F.; Carvalho Jr., A.A.; Peixoto, A.L.; Walter, B.M.T.; Bicudo, C.; Zappi, D.; Costa, D.P.; Lleras, E.; Martinelli, G.; Lima, H.C.; Prado, J.; Stehmann, J.R.; Baumgratz, J.F.A.; Pirani, J.R.; Sylvestre, L.; Maia, L.C.; Lohmann, L.G.; Queiroz, L.P.; Silveira, M.; Coelho, M.N.; Mamede, M.C.; Bastos, M.N.C.; Morim, M.P.; Barbosa, M.R.; Menezes, M.; Hopkins, M.; Secco, R.; Cavalcanti, T.B. \& Souza, V.C. 2010. Lista de espécies da flora do Brasil. Jardim Botânico do Rio de Janeiro. Disponível em < http://floradobrasil.jbrj. gov.br/2010/>. Acesso em 21 Set 2011.

Gomes, A.L. \& Pires-Zottarelli, C.L.A. 2006. Diversidade de Oomycota da Reserva Biológica de Paranapiacaba, Santo André, SP: primeiras citações para o Brasil. Revista Brasileira de Botânica 29: 569-567.

Gomes, A.L. \& Pires-Zottarelli, C.L.A. 2008. Oomycota (Straminipila) da Reserva Biológica de Paranapiacaba, Santo André, SP, Brasil. Acta Botanica Brasilica 22: 373-392.

Gomes, A.L.; Pires-Zottarelli, C.L.A.; Rocha, M. \& Milanez, A.I. 2003. Saprolegniaceae de áreas de Cerrado do estado de São Paulo, Brasil. Hoehnea 30: 95-110.

Hanson, A.M. 1944. Three new saprophytic chytrids. Torreya 44: 30-33.

Huneycutt, M.B. 1952. A new water mold on keratinized materials. Journal of the Elisha Mitchell Scientific Society 68: 109-112.

Joffily, J.M. 1947. Alguns ficomicetos aquáticos e terrícolas do Brasil. Boletim da Sociedade Brasileira de Agronomia 10: 95-120.

Johanson, A.E. 1944. An endo-operculate chytridiaceous fungus: Karlingia rosea gen. nov: American Journal of Botany 31: 397-404.

Johnson Jr., T.W.; Rogers, AL. \& Beneke, E.S. 1975. Aquatic fungi of Iceland: comparative morphology of Achlya radiosa, Achlya pseudoradiosa and Achlya stellata. Mycologia 67: 108-119.

Johnson Jr., T.W.; Seymour, R.L. \& Padgett, D.E. 2002. Biology and systematics of the Saprolegniaceae. Disponível em <http://www.uncw.edu/people/ Padgett/book $>$. Acesso em 10 Nov 2002.

Johnson Jr., T.W.; Seymour, R.L. \& Padgett, D.E. 2005. Systematics of the Saprolegniaceae: new taxa. Mycotaxon 92: 1-10. 
Karling, J.S. 1931. Studies in Chytridiales, VI: The occurrence and life history of a new species of Cladochytrium in cells of Eriocaulon septangulare. American Journal of Botany 18: 526-557.

Karling, J.S. 1944a. Brazilian chytrids, II: New species of Rhizidium. American Journal of Botany 31: 254-261.

Karling, J.S. 1944b. Brazilian chytrids, I: Species of Nowakowskiella. Bulletin of the Torrey Botanical Club 71: 374-389.

Karling, J.S. 1945a. Brazilian chytrids, VI: Rhopalophlyctis and Chytriomyces, two new operculate genera. American Journal of Botany 32: 362-369.

Karling, J.S. 1945b. Brazilian chytrids, V: Nowakowskiella macrospora sp., and other polycentric species. American Journal of Botany 32: 29-35.

Karling, J.S. 1946. Keratinophilic chytrids. American Journal of Botany 33: 219.

Karling, J.S. 1947a. Keratinophilic chytrids, II: Phlyctorhiza variabilis n. sp. American Journal of Botany 34: 27-32

Karling, J.S. 1947b. Brazilian chytrids, X: New species with sunken opercula. Mycologia 39: 56-70.

Karling, J.S. 1949. New monocentric eucarpic operculate chytrids from Maryland. Mycologia 41: 502-522.

Karling, J.S. 1965. Catenophlyctis, a new genus of the Catenariaceae. American Journal of Botany 52: 133-138.

Karling, J.S. 1977. Chytridiomycetarum Iconographia. J. Cramer, Vaduz, New York. 414p.

Kirk, P.M.; Cannon, P.F.; Minter, D.W. \& Stalpers, J.A. 2008. Dictionary of Fungi. 10 ed. CABI Bioscience, Wallingford. 771p.

Mendonça, R.R. 2004. A história da ocupação do interior do estado de São Paulo. In: Bitencourt, M.D. \& Mendonça, R.R (orgs.). Viabilidade de conservação dos remanescentes de Cerrado no estado de São Paulo. Fapesp, Annablume, São Paulo. Pp. 117-127.

Milanez, A.I. 1968. Aquatic fungi of the "Cerrado" region of São Paulo State, I: First results. Rickia 3: 97-109.

Milanez, A.I. 1970. Contributions to the knowledge of aquatic Phycomycetes of São Paulo State, I: Oomycetes form the west region. Rickia 5: 23-43.

Milanez, A.I. 1974. Notes on the genus Septosperma Whiffen ex Seymour. Rickia 6: 63-70.

Milanez, A.I. 1984. Fungos zoospóricos do estado de São Paulo, II: Chytridiomycetes da região oeste. Rickia 11: 115-127.

Milanez, A.I. 1989. Fungos de águas continentais. In: Fidalgo, O. \& Bononi, V.L. (coords.). Técnicas de coleta, preservação e herborização de material botânico. Instituto de Botânica, São Paulo (Série Documentos). Pp. 17-20.

Milanez, A.I.; Pires-Zottarelli, C.L.A. \& Gomes, A.L. 2007. Brazilian zoosporic fungi. Conselho Nacional de Pesquisa, São Paulo. 112p.
Milanez, A.I.; Schoenlein-Crusius, I.H.; TaukTornisielo, S.M. \& Trufem, S.F.B. 1997. Subgrupo e: microorgnismos (Fungos). In: Brito, M.C.W. (coord.). Bases para conservação e uso sustentável das áreas de Cerrado do estado de São Paulo. Secretaria do Meio Ambiente, São Paulo. Pp. 68-82.

Miranda, M.L. \& Pires-Zottarelli, C.L.A. 2008. O gênero Pythium no Parque Estadual da Serra da Cantareira, estado de São Paulo, Brasil. Hoehnea 35: 281-288.

Nascimento, C.A.; Gomes, E.P.C. \& Pires-Zottarelli, C.L.A. 2011a. Occurrence and distribution of zoosporic organisms in water bodies from Brazilian Cerrado. Mycologia 103: 261-272

Nascimento, C.A. \& Pires-Zottarelli, C.L.A. 2009. Chytridiales (Chytridiomycota) do Parque Estadual da Serra da Cantareira. Acta Botanica Brasilica 23: 459-473.

Nascimento, C.A. \& Pires-Zottarelli, C.L.A. 2010. Blastocladiales e Spizellomycetales do Parque Estadual da Serra da Cantareira, São Paulo, Brasil. Revista Brasileira de Botânica 33: 693-704.

Nascimento, C.A.; Souza, J.I.; Gomes, E.P.C. \& PiresZottarelli, C.L.A. 2011b. Zoosporic true fungi and heterotrophic straminipiles assemblages from soil of Brazilian Cerrado areas. Fungal Ecology, doi:10.1016/j.funeco.2011.08.001

Pires-Zottarelli, C.L.A. \& Gomes, A.L. 2007. Contribuição para o conhecimento de Chytridiomycota da Reserva Biológica de Paranapiacaba, Santo André, SP, Brasil. Biota Neotrópica 3: 309-329.

Pires-Zottarelli, C.L.A.; Gomes, A.L. \& Nascimento, C.A. 2007b. Entophlyctis luteolus in the Brazilian Atlantic Rainforest. Mycotaxon 99: 207-210.

Pires-Zottarelli, C.L.A.; Gomes, A.L.; Oliveira, J.M. \& Milanez, A.I. 2007a. Phragmosporangium uniseriatum in Brazil. Mycotaxon 102: 179-182.

Pires-Zottarelli, C.L.A. \& Milanez, A.I. 1993. Fungos zoospóricos da represa do Lobo ("Broa"): novas citações para o Brasil. Revista Brasileira de Botânica 16: 205-220.

Pires-Zottarelli, C.L.A. \& Rocha, M. 2007. Novas citações de Chytridiomycota e Oomycota para o Parque Estadual das Fontes do Ipiranga (PEFI), SP, Brasil. Acta Botanica Brasilica 21: 125-136.

Ratter, J.A.; Ribeiro, J.F. \& Bridgewater, S. 1997. The Brazilian Cerrado vegetation and threats to its biodiversity. Annals of Botany 80: 223-230.

Rocha, M. \& Pires-Zottarelli, C.L.A. 2002. Chytridiomycota e Oomycota da Represa de Guarapiranga, São Paulo, SP. Acta Botanica Brasilica 16: 287-309.

Rogers, A.L. \& Beneke, E.S. 1962. Two new species of Achlya in Brazil. Rickia 1: 243-249.

Rogers, A.L.; Milanez, A.I. \& Beneke, E.S. 1970. Additional aquatic fungi from São Paulo State. Rickia 5: 93-110. 
Schoenlein-Crusius, I.H.; Milanez, A.I.; Trufem, S.F.B.; Pires-Zottarelli, C.L.A; Grandi, R.P.; Santos, M.L. \& Giustra, K.C. 2006. Microscopic fungi in the Atlantic Rainforest in Cubatão, São Paulo, Brazil. Brazilian Journal of Microbiology 37: 244-252.

Secretaria do Meio Ambiente. 2000. Atlas das unidades de conservação ambiental do estado de São Paulo. Publicação do Governo do Estado de São Paulo, São Paulo.

Secretaria do Meio Ambiente. 2009. Assembléia Legislativa aprova Lei do Cerrado para o estado de São Paulo. Disponível em < http://www.ambiente. sp.gov.br/verNoticia.php?id=496>. Acesso em 10 Fev 2010.

Seymour, R.L. 1971. Studies on mycoparasitic chytrids, I: The genus Septosperma. Mycologia 63: 83-93.

Shearer, C.A.; Descals, E.; Kohlmeyer, B.; Kohlmeyer, J.; Marvanová, L.; Padgett, D.; Porter, D.; Raja,
H.A.; Schmit, J.P.; Thorton, H.A. \& Voglymayr, H. 2007. Fungal biodiversity in aquatic habitats. Biodiversity Conservation 16:49-67.

Sparrow Jr., F.K. 1957. A further contribution to the Phycomycete flora of Great Britain. Transactions of British Mycological Society 40: 523-535.

Sparrow Jr., F.K. 1960. Aquatic Phycomycetes. 2 ed. University of Michigan Press, Ann Arbor. 1187p.

Sparrow Jr.; F.K. \& Lange, L. 1976. Some bog chytrids. Canadian Journal of Botany 55: 1879-1890.

van der Plaats-Niterink, A.J. 1981. Monograph of genus Pythium. Studies in Mycology 21: 1-242.

Whiffen, A.J. 1942. Two new chytrid genera. Mycologia 34: 543-557.

Willoughby, L.G. 1961. The ecology of some lower fungi at Esthwaite water. Transactions of the British Mycological Society 44: 305-332.

Willoughby, L.G. 1965. A study of Chytridiales from Victorian and other Australian soils. Archive für Mikrobiology 52: 101-131. 